\title{
Pace of life syndrome under warming and pollution: integrating life history, behavior, and physiology across latitudes
}

\author{
Sara Debecker and Robby Stoks ${ }^{1}$ \\ Evolutionary Stress Ecology and Ecotoxicology, KU Leuven (University of Leuven), Charles Deberiotstraat 32, 3000 Leuven, Belgium
}

Citation: Debecker, S., and R. Stoks. 2019. Pace of life syndrome under warming and pollution: integrating life history, behavior, and physiology across latitudes. Ecological Monographs 89(1):e01332. 10.1002/ecm.1332

\begin{abstract}
To fully comprehend and predict the impact of drivers of global change such as climate warming and pollution, integrated multi-trait approaches are needed. As organismal traits are often correlated, responses to stressors are expected to induce coordinated changes in many traits. A promising framework to study this is the pace of life syndrome (POLS), which predicts the integration of life history, behavioral, and physiological traits along a fast-slow continuum. Using an integrative multi-trait approach, we evaluated the presence of a POLS both within and across latitudes and how POLS patterns are affected by warming and metal pollution. We studied this in Ischnura elegans damselfly larvae of replicated low- and high-latitude populations that strongly differ in voltinism (three to four generations per year vs. one generation every two years) reared in a common-garden experiment at two temperatures. Across latitudes, life history, behavior, and physiology covaried in accordance with the POLS, with the fast-paced low-latitude damselflies characterized by a fast growth rate, high activity, and more explorative and risk-taking behavior, fast metabolic rate, and low investment in immune function (activity of phenoloxidase). This fast POLS strategy was associated with a higher sensitivity to metal exposure and a higher vulnerability to predation. Warming caused opposite responses between the latitudes consistent with differential thermal adaptation in growth rate, behavior, and oxidative stress parameters. Despite this, damselflies of both latitudes showed a consistent pattern in phenotypic correlations among traits that, moreover, was not affected by warming and metal exposure. Within latitudes, there was no full support for the POLS. More active larvae were more explorative and risk taking, which aligned with the fast-slow life history axis, but less strong than at the across-latitude level. Physiological traits were also integrated within latitudes, yet there was no unambiguous coupling with the fastslow life history continuum. The consistent syndrome structure, if underpinned by genetic correlations, may restrict the independent evolution of individual traits, yet may not necessarily constrain adaptive evolution of integrated trait sets. This is because the covariance pattern was to a large extent similar across latitudes and within latitudes, suggesting adaptive trait integration guiding adaptive evolution of trait sets along the fast-slow continuum.
\end{abstract}

Key words: behavioral syndromes; boldness; correlational selection; geographical variation; gradual thermal evolution; life history trade-offs; phenotypic integration; physiological syndrome; space-for-time substitution; structural equation modeling.

\section{INTRODUCTION}

To understand and predict patterns in trait variation along environmental gradients and in response to anthropogenic stressors, the integration of traits into syndromes has received increasing attention (Carnicer et al. 2013, Killen et al. 2013, Stevens et al. 2014, Boyle et al. 2015). A syndrome can be defined as a set of covarying phenotypic traits at the level of species, populations or individuals and may include life history, behavior and physiology (Stevens et al. 2014). Many

Manuscript received 23 November 2016; revised 7 July 2018; accepted 23 July 2018; final version received date of 25 August 2018. Corresponding Editor: Sharon P. Lawler.

${ }^{1}$ Corresponding author; e-mail: robby.stoks@kuleuven.be types of syndromes have been identified, such as dispersal syndromes (Stevens et al. 2014), altitudinal syndromes (Hille and Cooper 2015), and island syndromes (Adler and Levins 1994, Doutrelant et al. 2016). The rationale for looking at syndromes is that organisms are integrated entities characterized by numerous and potentially correlated traits, and as a result, their plastic and evolutionary responses to selection pressures will involve coordinated changes in many traits (Schlichting and Pigliucci 1998, Schlichting and Wund 2014, Forsman 2015). To fully comprehend the impact of key drivers of global change on organisms, such as global warming and pollution (Tilman et al. 2001, Brook et al. 2008), one therefore needs to consider the integration of traits into coordinated syndromes (e.g., Stevens et al. 2013, Cayuela et al. 2016). 
A particularly well studied syndrome is the pace of life syndrome (POLS), this intuitive conceptual model based on verbal arguments predicts coevolved suites of life history, behavioral, and physiological traits along a fast-slow continuum both among individuals, populations, and species (Ricklefs and Wikelski 2002, Tieleman et al. 2005, Wiersma et al. 2007, Réale et al. 2010, Royauté et al. 2018). According to the POLS, a fast growth and development is associated with more active behaviors and physiological traits, such as a high metabolic rate, a high sensitivity to oxidative stress, and a low immune function (Ricklefs and Wikelski 2002, Réale et al. 2010). POLS studies rarely span the three main trait categories (but see, e.g., Tieleman et al. 2006, Royauté et al. 2015b) and are typically only based on a very limited number of traits per trait category, resulting in a fragmentary view. Moreover, not all POLS traits suggested to be integrated in the POLS by Réale et al. (2010) are backed up by theoretical POLS models (Mathot and Frankenhuis 2018), and support for the POLS has been mixed (Royauté et al. 2018).

Because of global warming, there is increasing interest in the intraspecific differentiation of populations along latitudinal gradients (De Frenne et al. 2013, Stoks et al. 2014). Populations generally show distinct life history strategies across latitudes as a result of distinct selective regimes (Blanckenhorn and Demont 2004, Conover et al. 2009). Therefore, consistent differences in population trait means are expected, this way forming a POLS across latitudes. However, while there is evidence for latitudinal POLS patterns among species (e.g., Tieleman et al. 2005, Wiersma et al. 2007, Londono et al. 2015, Ton and Martin 2015), this approach has rarely been explicitly used to study POLS patterns among populations (but see Wikelski et al. 2003). Moreover, it is unclear whether also the covariance patterns within populations differ across latitudes. The few studies looking at differences in within-population syndrome structure at different latitudes were limited to behaviors and revealed large similarities of covariation patterns across geographically distant populations (Pruitt et al. 2008, 2010, Alcalay et al. 2015, Bengston and Dornhaus 2015). However, whether such consistency of covariation patterns across latitudes is also true when including life history and physiological traits remains a significant gap in our knowledge. Thermal adaptation that is known to drive divergence in population trait means along latitudinal gradients (Angilletta 2009, Conover et al. 2009) may potentially also drive changes in POLS structure (Segev et al. 2017).

One central question under global warming is how organisms will be affected by the predicted temperature increase. Higher temperatures may increase or decrease growth rate, development rate, and metabolic rate in ectotherms depending on whether or not temperatures cross the thermal optima for these traits (Angilletta 2009, Tattersall et al. 2012); if these are part of a POLS, integrated changes in large trait sets are to be expected. Moreover, besides changes in trait means, the syndrome covariance structure might also change in response to altered environmental temperatures (Chappell et al. 2004, Biro et al. 2010, Killen et al. 2013, Segev et al. 2017). Yet surprisingly, no study so far has explicitly investigated how the POLS might change under global warming. In addition to such plastic responses, evolutionary responses are also important to consider when predicting how organisms will cope with global warming (Merilä and Hendry 2014). Thermal adaptation along latitudinal gradients is key to predict the effects of gradual thermal evolution in response to global warming. Indeed, it forms the basis of the space-for-time substitution approach, where temporal dynamics are extrapolated from spatial variation in local adaptation (Fukami and Wardle 2005). Using this approach, the low-latitude populations reared at their current high temperature provide a proxy for the response of the high-latitude populations under global warming in case of gradual thermal evolution. When applied to global warming, latitudes should be chosen so that the current temperature difference matches the predicted temperature increase at the high latitude under an IPCC warming scenario. While this approach has been successfully used to assess single trait changes to warming (Merilä and Hendry 2014), it has never been used for integrated trait syndromes.

Besides global warming, pollution is one of the important drivers of global change that threaten biodiversity (Brook et al. 2008). Moreover, these two stressors may interact synergistically (Sokolova and Lannig 2008, Noyes et al. 2009). As contaminants can be neurotoxic and strongly alter the energy balance and energy allocation patterns of organisms, they are likely to affect organisms' POLS by interfering with underlying trade-offs, such as the growth vs. body maintenance trade-off. From a more mechanistic point of view, contaminants may directly or indirectly interfere with physiological systems, e.g., through inhibition of acetylcholinesterase (Sarkar et al. 2006) or through the generation of oxidative stress (Lushchak 2011), in this way affecting life history, behavior, and physiology. The few studies that looked at how contaminants affect covariation between behavioral traits (e.g., Brodin et al. 2013, Montiglio and Royauté 2014, Royauté et al. 2015a) showed that contaminants can weaken covariation but also generate new behavioral covariation patterns. Although a wider role of contaminants in shaping trait associations has been suggested (Killen et al. 2013), only one study investigated how contaminants change covariation patterns between life history and behavior (Debecker et al. 2016). In the latter study, a positive association between fast life history and risk taking in the presence of predator cues arose only after a pesticide treatment but only in the most fast-lived species studied. This suggests that the sensitivity to contaminants might depend on the pace of life. A higher sensitivity of animals with a fast POLS could be expected for several reasons: fast-lived organisms might have a higher contaminant uptake because of a smaller size (hence large 
surface-to-volume ratio), a faster metabolic rate, a higher food intake, and a lower investment in body maintenance such as detoxification and repair mechanisms (Congdon et al. 2001, Canli and Atli 2003, Rubach et al. 2011, Baas and Kooijman 2015). However, the value of the POLS framework to predict sensitivity to contaminants in a warming world remains largely unexplored.

The general goal of the current study was to evaluate the presence of a POLS both within and across latitudes and how this is affected by warming and metal pollution. We thereby aimed at studying multiple traits spanning the three POLS trait categories (life history, behavior, and physiology). More specifically, using an integrative multi-trait approach we investigated (1) the presence of syndromes among the behavioral traits and among the physiological traits and an overarching POLS within and across latitudes through the evaluation of trait covariance structures (within latitudes) and trait means (across latitudes); (2) how the means and the covariance structure of the POLS traits were affected by warming and metal contamination, and whether this differed between latitudes; and (3) whether having a fast pace (fast-lived latitude/higher temperature) made animals more susceptible to metal contamination. We tested this in larvae of replicated low- and high-latitude populations of the damselfly Ischnura elegans in a common-garden warming experiment at two temperatures, representing the mean summer water temperatures at each of these latitudes, where we manipulated the absence and presence of zinc contamination. Zinc is one of the most commonly used metals in the world, resulting in frequent emissions to aquatic systems (Van Steertegem 2010, Brix et al. 2011). Moreover, zinc is known to affect life history, behavior, and physiology in damselflies (e.g., Dinh Van et al. 2013, Janssens et al. 2014a).

\section{Material And Methods}

\section{General overview of the experimental setup}

We performed a common-garden rearing experiment from the egg stage with Ischnura elegans damselfly larvae from two latitudes separated more than $1,500 \mathrm{~km}$. Larvae from each latitude were consistently reared and tested at $20^{\circ} \mathrm{C}$ or $24^{\circ} \mathrm{C}$ throughout the entire experiment. When a larva molted into the final instar, it was assigned to a sixday zinc exposure treatment. This resulted in a nested full factorial design with 3 populations per latitude $\times 2$ latitudes (high/Sweden and low/France) $\times 2$ temperatures $\left(20^{\circ} \mathrm{C}\right.$ and $\left.24^{\circ} \mathrm{C}\right) \times 2$ zinc treatments (zinc present and absent). After the zinc exposure period, metabolic rate was quantified and behavioral trials were performed for all larvae, followed by either a predation trial or quantification of a number of physiological variables. A timeline of the experiment is presented in the Supporting Information (Appendix S1: Fig. S1). Initial sample sizes varied between 73 and 97 larvae per combination of latitude, temperature, and zinc treatment, with a total of 669 larvae (for details: see Table S1 in Appendix S1). Final sample sizes per response variable can be lower because of mortality throughout the experiment.

\section{Study populations and rearing}

Eggs were collected in 2012 from three populations in southern Sweden and three populations in southern France, which represent high-latitude and low-latitude populations of this species in Europe (Gosden et al. 2011). Within this species, strong differentiation in life history has been documented in the field with high-latitude populations being semivoltine and low-latitude populations being multivoltine (Corbet et al. 2006); these differences have been shown to be paralleled under common-garden conditions (e.g., Shama et al. 2011). At the low latitude, we sampled Saint Martin de Crau $\left(43^{\circ} 37^{\prime} 57.88^{\prime \prime} \mathrm{N}, 4^{\circ} 46^{\prime} 55.18^{\prime \prime}\right.$ E), Laune des Irudes

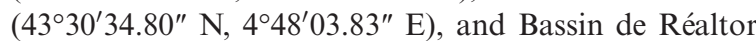
(43 $\left.28^{\prime} 11.16^{\prime \prime} \mathrm{N} / 05^{\circ} 19^{\prime} 44.16^{\prime \prime} \mathrm{E}\right)$ in southern France, and at the high-latitude Kalmar Dämme $\left(56^{\circ} 40^{\prime} 9.84^{\prime \prime} \mathrm{N}\right.$, $\left.16^{\circ} 17^{\prime} 48.48^{\prime \prime} \mathrm{E}\right)$, Svino (56 $\left.41^{\prime} 4.32^{\prime \prime} \mathrm{N}, 16^{\circ} 22^{\prime} 23.79^{\prime \prime} \mathrm{E}\right)$, and Hovgårdsdammarna $\left(57^{\circ} 15^{\prime} 1.78^{\prime \prime} \mathrm{N}, 12^{\circ} 8^{\prime} 1.98^{\prime \prime} \mathrm{E}\right)$ in southern Sweden.

Details of the biotic and abiotic variables of the study lakes can be found in Appendix S2. All study sites are slightly alkaline, shallow $(<2 \mathrm{~m})$ lakes with abundant aquatic vegetation. Study lakes did not differ between latitudes in the measured abiotic variables $(\mathrm{pH}$, oxygen levels, and chlorophyll $a$ levels), total prey biomass, and densities of key predators (fish and macroinvertebrate predators). The mean water temperatures in summer in these lakes are $\sim 24^{\circ} \mathrm{C}$ in Southern France and $\sim 20^{\circ} \mathrm{C}$ in Southern Sweden (Appendix S2; De Block et al. 2013, Dinh Van et al. 2014). The $4^{\circ} \mathrm{C}$ temperature difference between these latitudes matches the predicted temperature increase in southern Scandinavia by 2100 under IPCC scenario RCP8.5 (IPCC 2014). Therefore, the experimental setup allows a space-for-time substitution approach whereby the low-latitude populations reared at $24^{\circ} \mathrm{C}$ provide a proxy for the response of the high-latitude populations under global warming in case of gradual thermal evolution.

Concentrations of zinc in water and sediment were quantified with inductively coupled plasma optical emission spectrometry (ICP-OES; detection limits: water $<2.5 \mu \mathrm{g} / \mathrm{L}$, sediment $<0.063 \mu \mathrm{g} / \mathrm{g} \mathrm{dm}$ [dry mass]). In the French sites, zinc concentrations ranged from below the detection limit to $179.6 \mu \mathrm{g} / \mathrm{L}$ in water samples and from 3.17 to $5.36 \mu \mathrm{g} / \mathrm{g} \mathrm{dm}$ for sediment samples. In the Swedish sites, all water samples were below the detection limit and concentrations in the sediment samples ranged from below the detection limit to $2.44 \mu \mathrm{g} / \mathrm{g} \mathrm{dm}$. The observed sediment concentrations are very low compared to published background levels in Europe (EC 2010), whereas concentrations in the water were always much $(>800$ times) lower than the $\mathrm{LC}_{50}$ for the study species $\left(\mathrm{LC}_{50}\right.$ $144 \mathrm{~h}>150 \mathrm{mg} / \mathrm{L}$; Dinh Van et al. 2013). 
From each population, between 9 and 22 mated females (total of 94 families) were collected and placed individually in small jars with wet filter paper for oviposition. The resulting eggs were transferred to the laboratory in Belgium where they hatched. Larvae were placed individually in $200-\mathrm{mL}$ vials with dechlorinated tap water and assigned to a temperature treatment of $20^{\circ} \mathrm{C}$ or $24^{\circ} \mathrm{C}$. Throughout the rest of the experiment, the animals were kept at the assigned rearing temperature and a constant photoperiod of $14 \mathrm{~h}: 10 \mathrm{~h}$ light:dark. During the rearing period, the larvae were daily fed Artemia nauplii ad libitum (549 \pm 30 nauplii per feeding portion, mean $\pm \mathrm{SE}, n=40$ feeding portions) five days per week. The number of families per population included in the predation experiment varied between 9 and 21 (total of 90 families) and between 8 and 18 for the physiological data (total of 74 families).

\section{Zinc exposure period}

When a larva had molted into the final larval stage, it was assigned to a six-day zinc exposure period (days 06). One-half of the larvae per combination of population and temperature were randomly allocated to the control treatment and the other one-half was exposed to a nominal concentration of $100 \mathrm{mg} / \mathrm{L}$ zinc. This concentration was chosen because it reduces growth rate in I. elegans larvae (Dinh Van et al. 2013). Note that this Zn concentration is much higher than those measured in the collection sites. Throughout the exposure period, larvae were fed Artemia nauplii ad libitum daily.

Zinc solutions were prepared from a stock solution of $\mathrm{ZnCl}_{2}$ (5 $\mathrm{g}$ zinc/L dissolved in milli-Q water) that was stored in the dark at $4{ }^{\circ} \mathrm{C}$ and renewed monthly. To prepare exposure media, the stock solution was further diluted with synthetic pond water (for the composition, see Janssens and Stoks [2013]), which was also used as control medium. The larvae were exposed to $100 \mathrm{~mL}$ of the medium in the same vials as they had been reared in. To minimize concentration changes due to evaporation, the medium was renewed every two days. The measured zinc concentrations in the experimental vials when the medium was freshly renewed was $93.10 \pm 1.65 \mathrm{mg} / \mathrm{L}$ (mean $\pm \mathrm{SD}, n=5$ pooled start samples, taken throughout the experiment); after $48 \mathrm{~h}$ (just before renewal of the medium), the concentration was $95.31 \pm 2.84 \mathrm{mg} / \mathrm{L}$, as verified with ICP-OES.

\section{Growth rate}

We have previously shown that larval growth rate is well integrated with other life history traits, such as age and size at emergence and adult lifespan, along a fastslow life history continuum in I. elegans (Debecker et al. 2016). We therefore consider growth rate a reliable proxy for pace of life (see also Stamps 2007, Biro and Stamps 2008). We quantified growth rate across the 10-d experiment, i.e., from the start of the 6-d exposure period until
$4 \mathrm{~d}$ after the end of the exposure period. To quantify growth rates, each larva was weighed to the nearest $0.01 \mathrm{mg}$ using an electronic balance (Mettler Toledo AB135-S; Columbus, OH, USA). Individual growth rates were calculated as $\left(\ln _{\text {final mass }}-\ln _{\text {initial mass }}\right) / 10 \mathrm{~d}$ (see Stoks et al. 2012). Sample sizes for growth rate varied between 70 and 82 for each combination of latitude, temperature, and zinc treatment (total of 609 larvae).

\section{Behavioral trials}

During the three days after the zinc exposure period (days 7 to 9 of the experiment), we carried out six behavioral trials in the absence of zinc. The large number of larvae tested precluded us from estimating repeatability of the same behavior in the same individual. Yet, these behaviors have been shown to be repeatable (i.e., consistent when tested multiple times in the same animal under the same conditions) in the study species and related damselfly species (Slos and Stoks 2006, Brown and Robinson 2016, Debecker et al. 2016, Tüzün et al. 2017; I. Sanmartin-Villar et al., unpublished data). Note that we here focus on covariation patterns at the phenotypic level and how these may change between latitudes and under exposure to zinc and warming.

Exploratory behavior in a novel situation. - On day 7, the exploratory behavior of each larva was measured in two ways based on Dingemanse et al. (2007): (1) the distance covered in a novel environment and (2) the latency time for a larva to feed on a novel food item (while being in a familiar environment). We justify the use of these variables as estimates of exploratory behavior in Appendix S4, where we discuss how these metrics can be distinguished from the behaviors of acclimatized individuals. Each larva was transferred from its rearing vial to an observation container $(15 \times 10 \times 12.5 \mathrm{~cm})$ with $200 \mathrm{~mL}$ of synthetic pond water. A coordinate grid $(34 \times 21$ grid cells of $4.4 \times 4.8 \mathrm{~mm})$ was attached underneath each container. The container walls were covered with tape to prevent larvae from seeing each other (damselfly larvae are cannibalistic; De Block and Stoks 2004). The observation started within 5 min after transferring the larvae to their new environment. During $140 \mathrm{~min}$, the position of each larva's head was recorded every $10 \mathrm{~min}$. The resulting 15 positions per larva were analyzed with Image Pro Plus v5 (Media Cybernetics Inc., Rockville, MD, USA) to quantify the total distance covered.

Afterward, the larvae were transferred back to their rearing vial for the second behavioral test, which measured exploratory behavior toward a novel food item, namely a chironomid larva (since damselfly larvae were reared in the laboratory from the egg stage, they had never been in contact with chironomids before). After transferring the larvae to their rearing vial, they could re-acclimate for at least $60 \mathrm{~min}$ before a living chironomid was introduced. We subsequently timed how long it 
took for each damselfly larva to grab this new food item. The larvae (196 out of 628) that had not grabbed the chironomid within $30 \mathrm{~min}$ were assigned a value of $30 \mathrm{~min}$. Afterward, the damselfly larvae were again transferred to their observation container.

Activity in a non-risky and non-novel environment.-On day 8 , we again measured each larva's distance covered in the observation container. As the larvae had been transferred to these containers the previous day, current environment constitutes a non-novel environment and the distance covered can be interpreted as a measure of general activity (Brodin 2009). Afterward, the larvae were left in their observation containers until next day's observations.

Risk-taking behavior-On days 8-9, risk-taking behavior was measured in three ways: (1) the freeze time, i.e., the time to start moving again after an escape swimming bout (Brodin 2009), (2) the distance covered in the presence of olfactory predator cues (Brodin 2009), and (3) the feeding rate in the presence of olfactory and visual predator cues (Tüzün et al. 2015). These behaviors are known to be repeatable in the study species (Slos and Stoks 2006, Debecker et al. 2016; I. Sanmartin-Villar et al., unpublished data). As these behaviors increase access to resources at the cost of increased probability of being exposed to predators (see Results), they can be considered as reflecting boldness.

After the general activity test on day 8, risk taking was measured by quantifying the time inactive after escape swimming (following Brodin 2009). Each larva, still located in its familiar observation container, underwent a simulated predator attack by touching its lamellae with the tip of a plastic pipette thereby eliciting a swimming escape response (Gyssels and Stoks 2005). After the escape swimming bout ended, we measured the time that the larva remained motionless, i.e., the time between the larva stopped swimming and started moving again. The larvae that did not start moving within the first five minutes (114 out of 628) were given a cut-off value of $5 \mathrm{~min}$. Individuals that have a shorter latency time after the escape swimming bout are more risk taking.

On day 9, we again measured the distance covered in the familiar observation container, however, this time in the presence of olfactory predator cues (based on Brodin 2009). Hence, distance covered in this context can be interpreted as a measure of boldness (Réale et al. 2007). The predator cues were prepared by homogenizing one conspecific damselfly larva (wet mass of approximately $30 \mathrm{mg}$ ) in $20 \mathrm{~mL}$ of water in which a large Anax dragonfly predator had eaten a conspecific larva. Anax larvae are important predators of Ischnura larvae (Stoks et al. 2005). Two milliliters of this medium was added to the synthetic pond water $15 \mathrm{~min}$ prior to the start of the observations.

Afterward, we measured feeding rate in the presence of predator cues, closely following the protocol of
Janssens and Stoks (2013). For this, each larva was transferred to a $100 \mathrm{~mL}$ glass vial filled with synthetic pond water and was allowed to acclimate to this new environment during $1 \mathrm{~h}$. Four vials with damselfly larvae were placed inside a larger $(20 \times 26 \times 5 \mathrm{~cm})$ container in which a dragonfly predator was present that could freely move between the vials. Vials extended above the water surface in the container preventing predators entering the vials. Fifteen minutes prior to the start of the test, $1 \mathrm{~mL}$ of the previously described predator medium was added to each vial. This way, damselfly larvae could receive both visual and olfactory predator cues. The feeding trial started when $1 \mathrm{~mL}$ of standard solution of Artemia nauplii (549 \pm 30 nauplii per portion, mean $\pm \mathrm{SE}, n=40$ portions) was injected. After two hours, all damselfly larvae were removed from the glass vials and transferred back to their rearing vials. Afterward, the number of uneaten nauplii was counted and subtracted from the number at the start of the trial (determined as the average number present in two control vials per session) in order to calculate the total number of nauplii eaten per individual.

After each observation day, the larvae were fed Artemia. To guarantee ad libitum food, larvae were given either a normal daily dose (as previously described) when fed in their rearing vials (day 9) or a threefold dose when fed in the bigger experimental containers (days 7 and 8).

Predation trial.- To investigate the fitness consequences of a given pace of life, we measured survival times in the presence of a predator. On day 10, a large subset of the larvae $(n=395)$ were subjected to a lethal predation trial based on Janssens and Stoks (2012); the rest of the larvae $(n=232)$ were frozen at $-80^{\circ} \mathrm{C}$ for physiological analyses. Sample sizes for the predation trials varied between 48 and 54 damselfly larvae per combination of latitude, temperature, and zinc treatment (for each combination, we used 8 to 26 larvae per population). For the predation trial, individual larvae were transferred to a $9 \times 9 \mathrm{~cm}$ plastic container filled with $200 \mathrm{~mL}$ of synthetic pond water. Within this size of dishes, damselfly larvae are able to escape attacks from the sit-and-wait dragonfly predators (S. Debecker, personal observation). This setup allows detection of survival selection by dragonfly predators on behavior of damselfly larvae (Janssens and Stoks 2012), making it suitable to test the fitness consequences of the here scored behaviors in terms of survival.

After an acclimation time of $30 \mathrm{~min}$, a large Anax dragonfly predator was introduced. Subsequently, we measured the time that the predator needed to catch the damselfly larva. Observations were ended after $120 \mathrm{~min}$; the few larvae that survived until this moment (15 out of 395 ) received a score of $120 \mathrm{~min}$. We measured the size of each predator to the nearest $0.01 \mathrm{~mm}$ using a caliper to include as a correcting factor in the analyses (mean size $=31.32 \mathrm{~mm}, \mathrm{SD}=2.82$ ). Predator individuals (total $n=57$ ) were used several times and at both 
temperature treatments with at least $7 \mathrm{~d}$ between successive trials. They were last fed $48 \mathrm{~h}$ prior to the predation trial to homogenize hunger levels. Between trials, predators were kept at $22^{\circ} \mathrm{C} ; 24 \mathrm{~h}$ before being used in a trial they were acclimated to the associated test temperature $\left(20^{\circ} \mathrm{C}\right.$ or $\left.24^{\circ} \mathrm{C}\right)$. Given that Anax are sit-and-wait predators and the speed of the labium strike is not temperature sensitive (as this is driven by a hydraulic mechanism and not by muscle contraction; Tanaka and Hisada 1980), temperature effects on predation rates are likely to be driven by thermal effects on the behaviors of the prey (see also Gvoždík and Smolinský 2015).

\section{Physiological endpoints}

We assayed a large number of physiological variables: metabolic rate and traits related to investment in selfmaintenance (antioxidant enzymes, oxidative damage, energy storage, immune function and melanin content). The inclusion of oxidative stress parameters is motivated by the recognition of oxidative stress as a mediator of life history trade-offs (Monaghan et al. [2009]; for damselfly larvae, Janssens and Stoks [2018]) and the suggested integration of sensitivity to oxidative stress as part of the POLS, with high sensitivity associated with a fast pace (Réale et al. 2010). Melanin is a pigment that fulfils a variety of functions, such as immune defense, cuticular hardening, camouflage, and wound healing (Roulin 2014). Since it is energetically costly, it is often found to be involved in trade-offs (Cotter et al. 2004, Prokkola et al. 2013, Debecker et al. 2015). Detailed descriptions of the protocols for the quantification of physiological variables are presented in the Supporting Information (Appendix S3).

At the last day of the exposure period (day 6), we measured the routine metabolic rate (RMR; sensu Careau et al. 2014) using the methodology of Stoks et al. (2006a) at the rearing temperature and zinc treatment of the larva tested. Each individual's oxygen consumption was calculated as $\mathrm{O}_{2}$ consumption per $24 \mathrm{~h}$ per mg wet body mass. Samples size for respiration rate varied between 72 and 95 per combination of latitude, temperature, and zinc treatment (total of 653 larvae).

Prior to physiological assays, individual larvae were homogenized using a pestle, diluted 15 times (volume per mass) in phosphate buffer saline (PBS, $100 \mathrm{mmol} / \mathrm{L}$, $\mathrm{pH} 7.4)$ and centrifuged for $5 \min \left(16,100 \mathrm{~g} ; 4^{\circ} \mathrm{C}\right)$. The resulting supernatant was used in the assays. The total protein content of a sample was quantified using the Bio-Rad protein assay (Hercules, California, USA) based on the Bradford method (Bradford 1976).

We measured the activity of superoxide dismutase (SOD) and catalase (CAT), two key antioxidant enzymes in insects (Korsloot et al. 2004), and glutathione-Stransferase (GST), which plays a secondary antioxidant role by detoxifying ROS-damaged cellular components such as products of lipid peroxidation and organic hydroperoxides (Storey 1996, Korashy and El-Kadi
2006). For the SOD activity, we used the protocol of De Block and Stoks (2008), based on the SOD assay kit WST (Fluka, Buchs, Austria). SOD activities were expressed as units per mg larval wet mass with one unit of SOD defined as the amount of the enzyme that inhibits the reduction reaction of WST-1 with superoxide anion by $50 \%$. To measure CAT activity, we used the protocol of De Block and Stoks (2008). CAT activities were expressed as units per mg larval wet mass with one CAT unit defined as the amount of enzyme needed to decompose $1 \mu \mathrm{mol} \mathrm{H}_{2} \mathrm{O}_{2}$ per min. The activity of GST was measured based on the protocol of McLoughlin et al. (2000). GST activity was expressed in units per mg larval wet mass with 1 unit representing $1 \mu \mathrm{mol}$ GSDNB formed per minute.

We measured oxidative damage to lipids and proteins by measuring two often used biomarkers: the formation of malondialdehyde (MDA) for lipid peroxidation, and the formation of protein carbonyl groups (Monaghan et al. 2009). MDA was measured as the formation of TBAMDA complexes using the TBA assay method for HPLC (Miyamoto et al. 2011). Values for oxidative damage to lipids were expressed as pmol MDA per mg larval wet mass. The formation of protein carbonyl groups was measured using the Oxiselect Protein Carbonyl ELISA kit (Cell Biolabs, San Diego, CA, USA) following the protocol provided by the manufacturer. Carbonyl concentrations were expressed as pmol carbonyl per mg larval wet mass.

Total fat content was measured based on the protocol of Bligh and Dyer (1959). Fat concentrations were expressed as $\mu \mathrm{g}$ fat per mg wet mass. Measurements of melanin were based on the protocol of Zhou et al. (2012). Melanin content was expressed as the amount of melanin in $\mu \mathrm{g}$ per mg larval wet mass.

We quantified the activity of phenoloxidase (PO), a key component of an insect's immune system (González-Santoyo and Córdoba-Aguilar 2012), using a modified version of the protocol by Stoks et al. (2006b). PO activity was expressed in units per mg wet mass with 1 unit representing the dose where $1 \mu \mathrm{mol}$ dopachrome is formed per minute.

Samples sizes per combination of latitude, temperature and zinc treatment varied between 27 and 32 (total of 232 larvae) for all molecular/physiological endpoints, except for carbonyl, for which samples size in each treatment group was 11 (total of 88 larvae) given the high cost of the assay.

\section{Statistical analyses}

Effects of latitude, rearing temperature, and the zinc treatment and their interactions on all response variables were analyzed with (generalized) linear mixed models, (G)LMMs, using the lme4 package version 1.1-6 (Bates et al. 2014) in R 3.0.1 (R Core Team 2013). In all models, population nested in latitude was included as a random factor. For the analysis of mortality, we ran a loglinear GLMM with binomial error distribution. When 
analyzing the behaviors, we added body mass as a covariate. When analyzing survival times under predation, we added both the mass of the damselfly larvae and the size of the predator as covariates. In the models of enzyme activities as well as protein carbonyl concentration, protein content was included as a covariate, whereas fat content was used as a covariate in the model testing for effects on lipid peroxidation (malondialdehyde, MDA). To meet model assumptions, several variables were log-transformed (see figures) and MDA was Box-Cox transformed $(\lambda=-0.304)$. As measure of effect sizes, we provided partial eta-squared $\left(\eta_{p}^{2}\right)$ values to all GLMM tables as suggested by Lakens (2013).

Given that many larvae did not capture the new food item within $30 \mathrm{~min}$ or did not start moving within $5 \mathrm{~min}$ after the escape swimming bout, we additionally analyzed these data as binary response variables. Latency time was recoded as 0 when no capture occurred within $30 \mathrm{~min}$ and as 1 when capture occurred within $30 \mathrm{~min}$. Freeze time after an escape swimming bout was recoded as 0 when larvae did start moving within $5 \mathrm{~min}$ and as 1 when larvae did not start moving within $5 \mathrm{~min}$. We analyzed both recoded binary variables with a binomial error structure and the logit link. These analyses largely confirmed the results of the LMM with actual latency times and freeze times (see Appendix S5).

We used structural equation models (SEM) on the raw data to analyze (1) the covariance structure of the traits at the phenotypic level, i.e., the POLS structure, (2) which of the (behavioral) traits predicted survival time in the presence of a dragonfly predator, and whether (1) and (2) were consistent across latitudes, temperatures, and zinc treatments. For both the POLS model and the predation model, we followed a similar general approach. First, to evaluate whether treatment groups had the same covariance structure (hence to test for effects of latitude, temperature, and zinc on the covariance structure), we selected the appropriate grouping structure by comparing models with different combinations of factor loadings constrained to be equal vs. freely varying across treatment groups. Second, we fitted the (POLS or predation) model using this grouping structure. All factor loadings were standardized. SEM analyses were done using the package lavaan version 0.5-17 (Rosseel 2012) in R 3.0.1 ( $\mathrm{R}$ Core Team 2013).

Specifically, we used multigroup SEMs (Shipley 2002) with eight groups, each of them being a specific combination of latitude, rearing temperature, and zinc treatment, to test for global differences in model structure between the treatment groups. For each SEM, eight alternative models were compared (Table 1): (I) loadings constrained to be equal across all treatment groups; (II-IV) loadings allowed to differ ("free") between both levels of one treatment (latitude/temperature/zinc) while keeping other loadings constrained; (V-VII) loadings free for two treatment groups; and (VIII) all loadings free. For example, the finding of model II as the best-fitting model would indicate that animals from different latitudes showed a different covariance structure, whereas temperature and zinc exposure did not affect covariance structure.

We compared models using two information criteria that avoid overfitting the data (Burnham and Anderson 2002, Aho et al. 2014): $\mathrm{AIC}_{\mathrm{c}}$ (Akaike information criterion corrected for small sample sizes) and $\mathrm{BIC}$ (Bayesian information criterion). While $\mathrm{AIC}_{\mathrm{c}}$ is recommended to be used as a standard approach (Burnham and Anderson 2002), more recently BIC has been advocated when comparing models to test hypotheses (i.e., linked to our treatments) and when models are based on controlled experiments (Aho et al. 2014, 2017), as we did in current study. Differences in $\mathrm{AIC}_{\mathrm{c}}$ or $\mathrm{BIC}$ between two models larger than 2 can be seen as more support for the model with the lowest value. Models $>10$ units from the model with lowest AIC or BIC have essentially no support (Burnham and Anderson 2004).

The full, overarching SEM that tested for covariation between life history, behavior, and physiology (Fig. 1)

TABLE 1. Alternative structural equation models (SEMs) to test for differences in model structure across treatments (latitude, temperature, zinc).

\begin{tabular}{|c|c|c|c|c|c|c|c|c|c|}
\hline \multirow[b]{3}{*}{ Model } & \multirow[b]{3}{*}{ Model } & \multicolumn{4}{|c|}{ France } & \multicolumn{4}{|c|}{ Sweden } \\
\hline & & \multicolumn{2}{|c|}{$20^{\circ} \mathrm{C}$} & \multicolumn{2}{|c|}{$24^{\circ} \mathrm{C}$} & \multicolumn{2}{|c|}{$20^{\circ} \mathrm{C}$} & \multicolumn{2}{|c|}{$24^{\circ} \mathrm{C}$} \\
\hline & & Control & Zinc & Control & Zinc & Control & Zinc & Control & Zinc \\
\hline I & all loadings constrained equal across treatments & A & A & A & A & A & A & A & A \\
\hline II & loadings free across latitudes & A & A & A & A & $\mathrm{B}$ & $\mathrm{B}$ & B & $\mathrm{B}$ \\
\hline III & loadings free across temperatures & A & A & $\mathrm{B}$ & $\mathrm{B}$ & A & A & $\mathrm{B}$ & $\mathrm{B}$ \\
\hline IV & loadings free across zinc levels & A & $\mathrm{B}$ & A & $\mathrm{B}$ & A & $\mathrm{B}$ & A & $\mathrm{B}$ \\
\hline $\mathrm{V}$ & loadings free across latitudes and temperatures & A & A & $\mathrm{B}$ & $\mathrm{B}$ & $\mathrm{C}$ & $\mathrm{C}$ & $\mathrm{D}$ & $\mathrm{D}$ \\
\hline VI & loadings free across latitudes and zinc levels & A & $\mathrm{B}$ & A & $\mathrm{B}$ & $\mathrm{C}$ & $\mathrm{D}$ & $\mathrm{C}$ & $\mathrm{D}$ \\
\hline VII & loadings free across temperature and zinc levels & A & $\mathrm{B}$ & $\mathrm{C}$ & $\mathrm{D}$ & A & $\mathrm{B}$ & $\mathrm{C}$ & $\mathrm{D}$ \\
\hline VIII & all loadings free & A & B & $\mathrm{C}$ & $\mathrm{D}$ & $\mathrm{E}$ & $\mathrm{F}$ & $\mathrm{G}$ & $\mathrm{H}$ \\
\hline
\end{tabular}

Notes: Each alternative model was a multigroup SEM with eight treatment groups (all combinations of two latitude, two rearing temperatures, and two zinc treatments), characterized by a different combination of factor loadings being constrained or free across these groups. Cells sharing the same letters indicate equal factor loadings. 


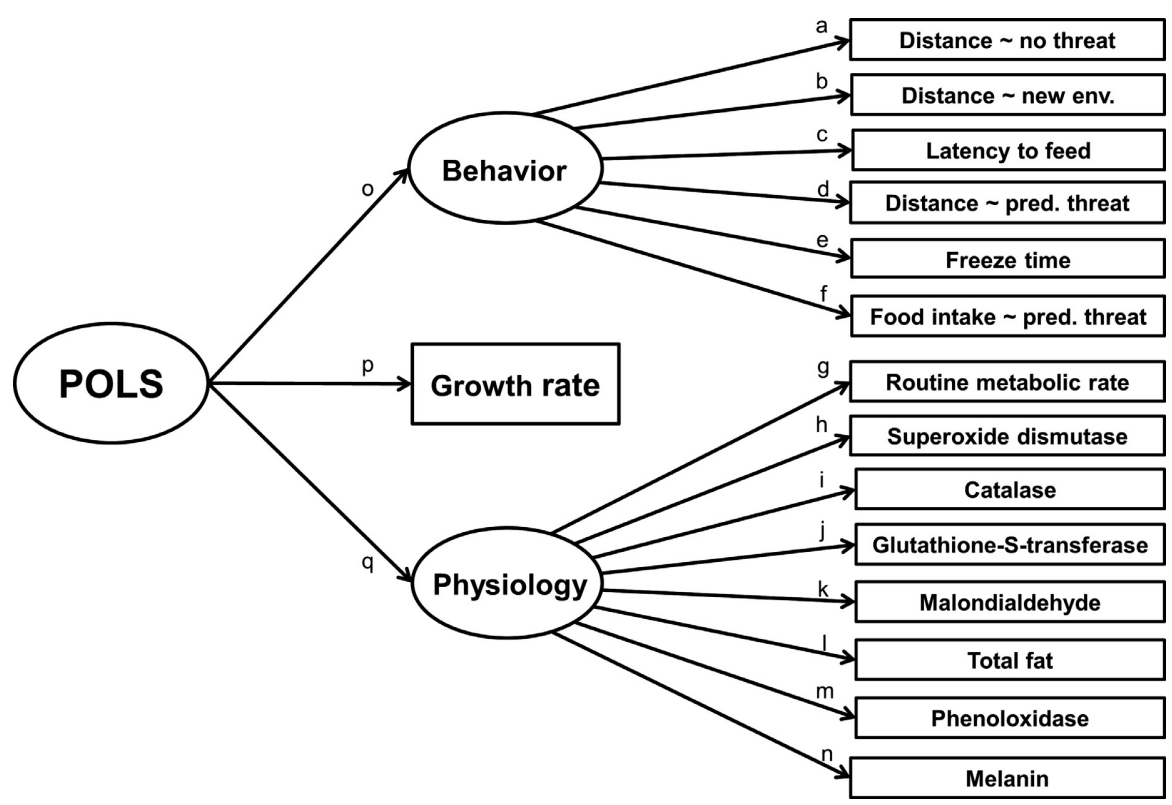

FIG. 1. Full structural equation model (SEM) structure, consisting of a behavioral syndrome (paths a-f), a physiological syndrome (paths $\mathrm{g}-\mathrm{n}$ ), and an overarching syndrome integrating behavior, life history, and physiology (paths o-q). POLS, pace of life syndrome; env., environment; pred., predator.

was constructed using a stepwise hierarchical approach, this way avoiding oversimplification by imposing the same grouping structure across the entire model. First, using the method described above to derive grouping structure, separate models were constructed for behavioral (Fig. 1, paths a-f) and physiological traits (paths $\mathrm{g}-\mathrm{n}$ ), with the behavioral/physiological model structure statistically modelled as latent variable. Carbonyl was not included in the model, because of its low sample size. The best models for behavior and physiology were then incorporated into the overarching model that tested for treatment effects on paths $\mathrm{o}-\mathrm{q}$, here with the pace of life syndrome structure as the latent variable. We did not include population as a factor when selecting the best SEM models as this would inflate the number of estimated parameters. Instead, after having selected the best overarching SEM model, we tested whether loadings were equal across populations within a given latitude. This was done by comparing per latitude the fit of the best model when loadings were set equal across populations within that latitude compared to when loadings were allowed to vary freely across populations within that latitude.

\section{Results}

\section{Survival and growth rate}

Zinc exposure reduced survival (integrated over the 6d exposure and 4-d post-exposure period) by ca. $10 \%$ (main effect Zinc; Table 2, Fig. 2). Survival was ca. $6 \%$ lower at $24^{\circ} \mathrm{C}$ than at $20^{\circ} \mathrm{C}$ (Table 2, Fig. 2). Both the zinc and the temperature effects did not differ between latitudes (all interactions, $P \geq 0.38$, Table 2).

French larvae grew faster than Swedish (main effect Latitude; Table 2, Fig. 2). The French larvae increased their growth rate at $24^{\circ} \mathrm{C}$ compared to $20^{\circ} \mathrm{C}$, while the Swedish larvae slowed down growth at $24^{\circ} \mathrm{C}$ (Latitude $\times$ Temperature, Table 2, Fig. 2). Zinc exposure decreased growth rate (main effect Zinc), and this was stronger in the French larvae (Latitude $\times$ Zinc; Table 2, Fig. 2).

\section{Behavior}

All behaviors, except freeze time after an escape swimming bout, differed between French and Swedish larvae (main effect Latitude; Tables 3 and 4): French larvae covered longer distances in all three types of environments, had shorter latencies to feed on a novel food item and had a higher food intake under predation threat than Swedish larvae (Fig. 3a-d, f).

At $24^{\circ} \mathrm{C}$ latency to feed and freeze time were shorter than at $20^{\circ} \mathrm{C}$ (Tables 3 and 4, Fig. 3d, e), and this to the same extent in larvae from both latitudes (Latitude $\times$ Temperature; both $P \geq 0.12$ ). For three behaviors, however, the effect of temperature was opposite between French and Swedish larvae; whereas French larvae increased their distance covered in both a novel environment and under predation threat, and also increased their foraging rate under predation threat at $24^{\circ} \mathrm{C}$ compared to $20^{\circ} \mathrm{C}$, the Swedish larvae showed a decrease in these behaviors at the higher temperature (Latitude $\times$ Temperature; all $P \leq 0.0015$; Fig. 3a, c, f). The 
TABLE 2. Results of the (general) linear mixed models ([G]LMMs) testing for the effect of latitude, rearing temperature, and zinc exposure on larval survival and growth rate during the rearing experiment and survival times during the predation trials in Ischnura elegans.

\begin{tabular}{|c|c|c|c|c|c|c|c|c|c|c|c|c|}
\hline \multirow[b]{2}{*}{ Factor } & \multicolumn{4}{|c|}{ Survival } & \multicolumn{4}{|c|}{ Growth rate } & \multicolumn{4}{|c|}{$\begin{array}{l}\text { Survival during the predation } \\
\text { trials }\end{array}$} \\
\hline & $\mathrm{df}$ & $\chi^{2}$ & $P$ & $\eta_{p}^{2}$ & $\mathrm{df}$ & $\chi^{2}$ & $P$ & $\eta_{p}^{2}$ & $\mathrm{df}$ & $\chi^{2}$ & $P$ & $\eta_{p}^{2}$ \\
\hline Latitude (Lat) & 1 & 1.37 & 0.24 & 0.0023 & 1 & 137.78 & $<0.001$ & 0.19 & 1 & 5.14 & 0.023 & 0.010 \\
\hline Temperature (Temp) & 1 & 5.92 & 0.015 & 0.018 & 1 & 0.43 & 0.51 & 0.0012 & 1 & 3.74 & 0.053 & 0.0031 \\
\hline Zinc $(\mathrm{Zn})$ & 1 & 16.86 & $<0.001$ & 0.042 & 1 & 88.46 & $<0.001$ & 0.13 & 1 & 1.12 & 0.29 & 0.0017 \\
\hline Lat $\times$ Temp & 1 & 0.13 & 0.72 & $<0.001$ & 1 & 83.53 & $<0.001$ & 0.12 & 1 & 6.33 & 0.012 & 0.016 \\
\hline Lat $\times \mathrm{Zn}$ & 1 & 0.11 & 0.74 & $<0.001$ & 1 & 5.35 & 0.021 & 0.0090 & 1 & 2.36 & 0.12 & 0.0060 \\
\hline Temp $\times \mathrm{Zn}$ & 1 & 0.36 & 0.55 & $<0.001$ & 1 & 1.24 & 0.27 & 0.020 & 1 & 0.052 & 0.82 & $<0.001$ \\
\hline Lat $\times$ Temp $\times \mathrm{Zn}$ & 1 & 0.44 & 0.38 & 0.0020 & 1 & 0.43 & 0.51 & $<0.001$ & 1 & 0.51 & 0.48 & 0.0013 \\
\hline Body mass & & & & & & & & & 1 & 5.60 & 0.018 & 0.016 \\
\hline Predator size & & & & & & & & & 1 & 0.015 & 0.90 & $<0.001$ \\
\hline
\end{tabular}

Notes: Significant $P$ values $(P<0.05)$ are printed in boldface type. $\eta_{p}^{2}$-values represent effect sizes.

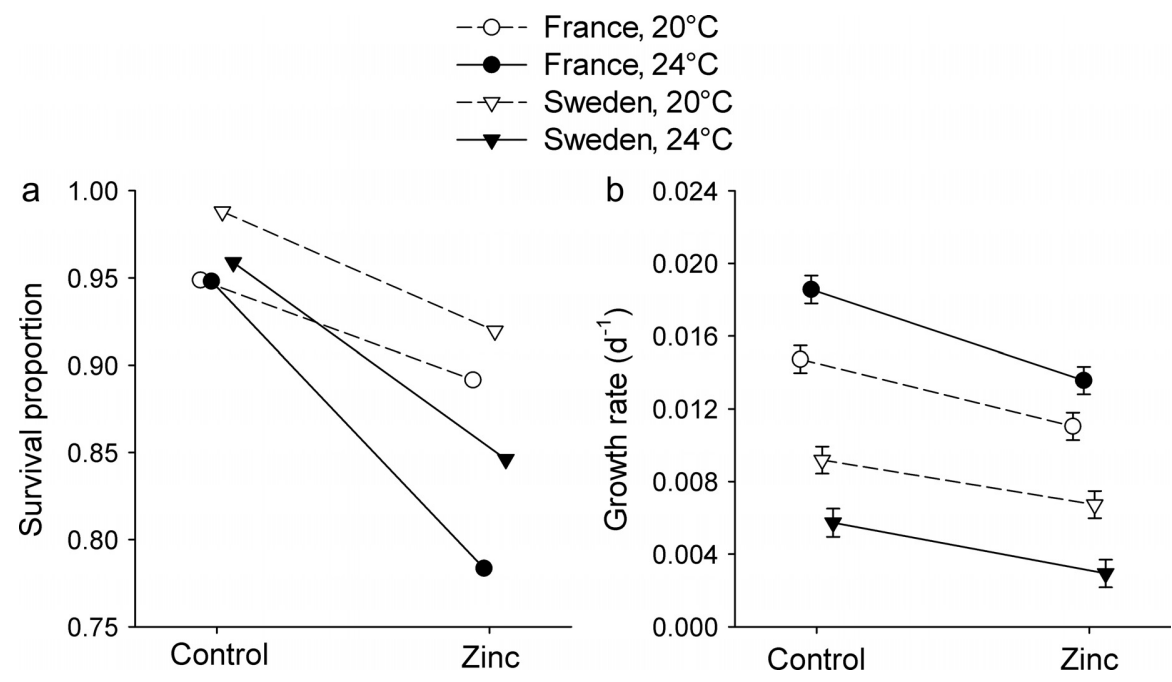

FIg. 2. (a) Proportion survival and (b) growth rate (mean \pm SE) of Ischnura elegans larvae in the final instar during and after a six-day exposure to zinc, as a function of latitude, rearing temperature, and zinc exposure.

TABLE 3. Results of the linear mixed models (LMMs) testing for the effect of latitude, rearing temperature, and zinc exposure on three behavioral traits (expressing activity and exploration) in Ischnura elegans.

\begin{tabular}{|c|c|c|c|c|c|c|c|c|c|c|c|c|}
\hline \multirow[b]{3}{*}{ Factor } & \multicolumn{4}{|c|}{ Activity } & \multicolumn{8}{|c|}{ Exploration } \\
\hline & \multicolumn{4}{|c|}{$\begin{array}{l}\text { Distance } \sim \text { non-novel } \\
\text { environment, no threat }\end{array}$} & \multicolumn{4}{|c|}{ Distance $\sim$ novel environment } & \multicolumn{4}{|c|}{ Latency to feed $\sim$ novel food item } \\
\hline & $\mathrm{df}$ & $\chi^{2}$ & $P$ & $\eta_{p}^{2}$ & $\mathrm{df}$ & $\chi^{2}$ & $P$ & $\eta_{p}^{2}$ & $\mathrm{df}$ & $\chi^{2}$ & $P$ & $\eta_{p}^{2}$ \\
\hline Latitude (Lat) & 1 & 20.51 & $<0.001$ & 0.029 & 1 & 62.82 & $<0.001$ & 0.090 & 1 & 16.67 & $<0.001$ & 0.026 \\
\hline Temperature (Temp) & 1 & 1.59 & 0.21 & $<0.001$ & 1 & 0.0007 & 0.98 & $<0.001$ & 1 & 7.24 & 0.0071 & 0.010 \\
\hline $\operatorname{Zinc}(\mathrm{Zn})$ & 1 & 17.02 & $<0.001$ & 0.030 & 1 & 27.99 & $<0.001$ & 0.047 & 1 & 23.33 & $<0.001$ & 0.039 \\
\hline Lat $\times$ Temp & 1 & 1.07 & 0.30 & 0.0018 & 1 & 8.93 & 0.0028 & 0.015 & 1 & 1.26 & 0.26 & 0.0021 \\
\hline Lat $\times \mathrm{Zn}$ & 1 & 0.098 & 0.75 & $<0.001$ & 1 & 0.21 & 0.65 & $<0.001$ & 1 & 0.0065 & 0.94 & $<0.001$ \\
\hline Temp $\times \mathrm{Zn}$ & 1 & 0.83 & 0.36 & 0.0014 & 1 & 0.0001 & 0.99 & $<0.001$ & 1 & 0.68 & 0.41 & 0.0011 \\
\hline Lat $\times$ Temp $\times \mathrm{Zn}$ & 1 & 0.79 & 0.37 & 0.0013 & 1 & 0.065 & 0.80 & $<0.001$ & 1 & 0.17 & 0.68 & $<0.001$ \\
\hline Body mass & 1 & 3.50 & 0.062 & 0.0066 & 1 & 1.93 & 0.16 & 0.0050 & 1 & 0.57 & 0.45 & 0.0013 \\
\hline
\end{tabular}

Notes: Significant $P$ values $(P<0.05)$ are printed in boldface type. $\eta_{p}^{2}$-values represent effect sizes. 
TABLE 4. Results of the linear mixed models (LMMs) testing for the effect of latitude, rearing temperature, and zinc exposure on three behavioral traits expressing risk taking in Ischnura elegans.

\begin{tabular}{|c|c|c|c|c|c|c|c|c|c|c|c|c|}
\hline \multirow[b]{3}{*}{ Factor } & \multicolumn{12}{|c|}{ Boldness } \\
\hline & \multicolumn{4}{|c|}{ Distance $\sim$ predation threat } & \multicolumn{4}{|c|}{$\begin{array}{c}\text { Freeze time after escape swim- } \\
\text { ming bout }\end{array}$} & \multicolumn{4}{|c|}{ Food intake $\sim$ predation threat } \\
\hline & $\mathrm{df}$ & $\chi^{2}$ & $P$ & $\eta_{p}^{2}$ & $\mathrm{df}$ & $\chi^{2}$ & $P$ & $\eta_{p}^{2}$ & $\mathrm{df}$ & $\chi^{2}$ & $P$ & $\eta_{p}^{2}$ \\
\hline Latitude (Lat) & 1 & 56.23 & $<0.001$ & 0.082 & 1 & 1.08 & 0.30 & 0.0039 & 1 & 57.58 & $<0.001$ & 0.076 \\
\hline Temperature (Temp) & 1 & 3.00 & 0.083 & 0.0024 & 1 & 18.51 & $<0.001$ & 0.044 & 1 & 0.79 & 0.37 & 0.0093 \\
\hline Zinc (Zn) & 1 & 6.80 & 0.0091 & 0.013 & 1 & 4.09 & 0.043 & 0.0087 & 1 & 19.08 & $<0.001$ & 0.038 \\
\hline Lat $\times$ Temp & 1 & 9.72 & 0.0018 & 0.016 & 1 & 2.93 & 0.087 & 0.0048 & 1 & 9.58 & 0.0020 & 0.016 \\
\hline Lat $\times \mathrm{Zn}$ & 1 & 1.19 & 0.28 & 0.0018 & 1 & 0.058 & 0.81 & $<0.001$ & 1 & 0.30 & 0.58 & $<0.001$ \\
\hline Temp $\times \mathrm{Zn}$ & 1 & 3.02 & 0.082 & 0.0049 & 1 & 0.10 & 0.75 & $<0.001$ & 1 & 0.15 & 0.70 & $<0.001$ \\
\hline Lat $\times$ Temp $\times \mathrm{Zn}$ & 1 & 1.43 & 0.23 & 0.0024 & 1 & 0.41 & 0.52 & $<0.001$ & 1 & 0.014 & 0.91 & $<0.001$ \\
\hline Body mass & 1 & 1.96 & 0.16 & 0.0050 & 1 & 6.79 & 0.0092 & 0.0099 & 1 & 15.99 & $<0.001$ & 0.030 \\
\hline
\end{tabular}

Notes: Significant $P$ values $(P<0.05)$ are printed in boldface type. $\eta_{p}^{2}$-values represent effect sizes.
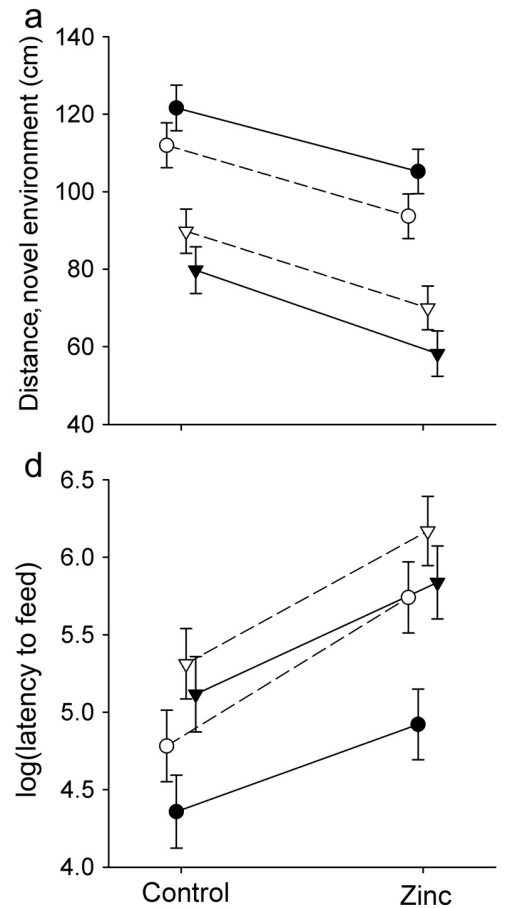
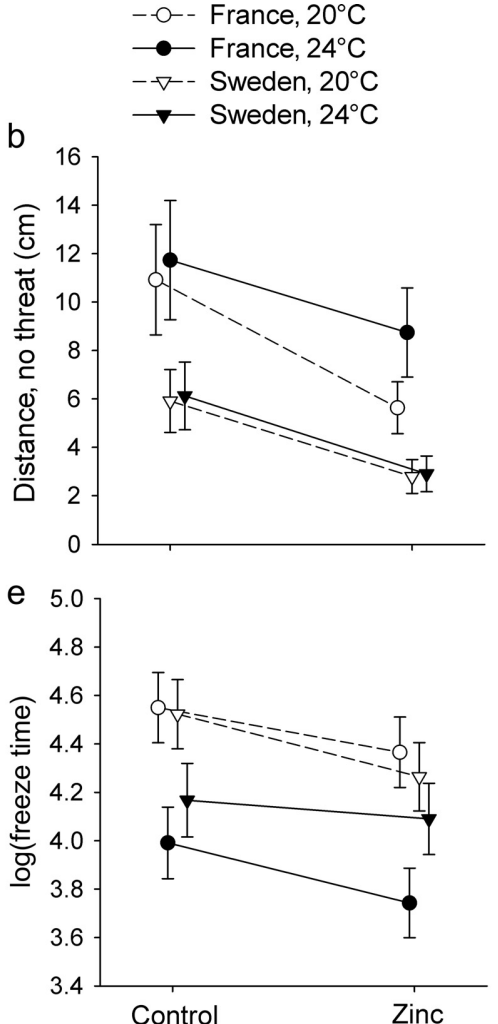

C
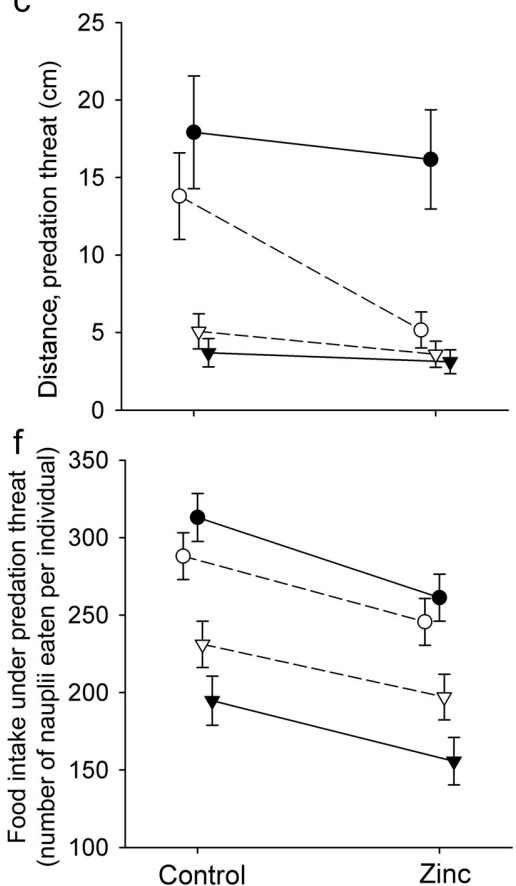

FIG. 3. Levels of six behavioral traits (expressing exploration, activity, and boldness [mean \pm SE]) of Ischnura elegans larvae as a function of latitude, rearing temperature, and zinc exposure: (a) distance covered in a novel environment, (b) distance covered in a non-novel and non-risky environment, (c) distance covered under predation threat, (d) latency to feed on a novel food item (measured in s), (e) freeze time after an escape swimming bout (measured in s), and (f) food intake under predation threat. Values are LS means corrected for body mass.

distance covered in the absence of predation threat was not temperature dependent (Tables 3 and 4 ).

Zinc exposure affected all measured behaviors (main effect Zinc; Table 3): it reduced the distance larvae covered in all three types of environments (Fig. 3a-c), increased the latency to feed on a new food item
(Fig. 3d), and reduced both freeze time and food intake under predation threat (Fig. 3e, f). The effects of zinc exposure on behavior did not differ between French and Swedish larvae (Latitude $\times$ Zinc: all $P \geq 0.29$ ), nor between temperature treatments (Temperature $\times$ Zinc; all $P \geq 0.059$ ). 
a

b
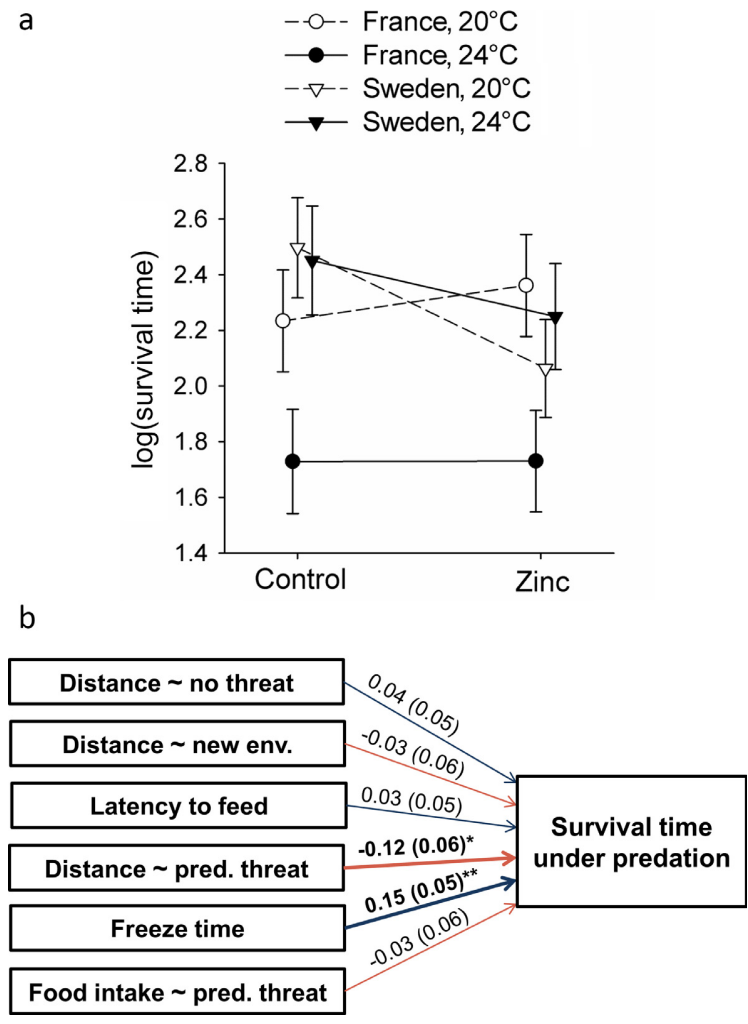

FIG. 4. (a) Survival times (mean $\pm \mathrm{SE}$; measured in minutes) of Ischnura larvae in a predation trial with an Anax predator as a function of latitude, rearing temperature, and zinc exposure; (b) structural equation model (SEM) showing the contribution of the behaviors in explaining survival times in the predation assay; this pattern was consistent across latitudes, rearing temperatures, and zinc exposure. Values are LS means corrected for damselfly body mass and predator size.

\section{Survival times under predation}

Survival times in the predation trials did not differ between French and Swedish larvae at $20^{\circ} \mathrm{C}$. At $24^{\circ} \mathrm{C}$, however, French larvae had shorter survival times than
TABLE 5. Model comparison results for the structural equation models (SEMs) of the predation data.

\begin{tabular}{lcccc}
\hline \hline Model & $\mathrm{AIC}_{\mathrm{c}}$ & $\Delta \mathrm{AIC}_{\mathrm{c}}$ & $\mathrm{BIC}$ & $\Delta \mathrm{BIC}$ \\
\hline I & 7117.45 & 0 & 7201.92 & 0 \\
II & 7124.11 & 6.69 & 7230.67 & 28.74 \\
III & 7126.32 & 8.90 & 7232.88 & 30.95 \\
IV & 7127.22 & 9.79 & 7233.77 & 31.85 \\
V & 7144.01 & 26.58 & 7293.26 & 91.33 \\
VI & 7142.11 & 24.68 & 7291.36 & 89.43 \\
VII & 7148.48 & 31.05 & 7297.73 & 95.80 \\
VIII & 7172.35 & 54.93 & 7321.60 & 119.68 \\
\hline
\end{tabular}

Note: Each alternative model tested for a different combination of factor loading constraints across treatment groups (latitude/temperature/zinc), as presented in Table 1. The best model (as indicated by the lowest Akaike information criterion corrected for sample size $\left[\mathrm{AIC}_{\mathrm{c}}\right]$ and Bayesian information criterion $[\mathrm{BIC}]$ values) is indicated in boldface type.

at $20^{\circ} \mathrm{C}$ and also shorter survival times than Swedish larvae (Latitude $\times$ Temperature; Table 2, Fig. 4a).

The SEM analysis showed that most support was found for model I, indicating no differences in model structure for survival times between latitudes, temperatures, or zinc treatments (Table 5). Two behaviors, both representing risk taking, significantly explained differences in survival times: larvae that covered a shorter distance in the presence of predator cues and had a longer freeze time after an escape swimming bout had a longer survival time in the presence of a predator (Fig. 4b).

\section{Physiology}

Overall, routine metabolic rate (RMR) was $\sim 51 \%$ higher at $24^{\circ} \mathrm{C}$ than at $20^{\circ} \mathrm{C}$ and $\sim 29 \%$ higher in French larvae than in Swedish larvae (main effects Temperature and Latitude; Table 6). Zinc exposure increased the RMR of Swedish larvae, while it rather decreased those of French larvae (Latitude $\times$ Zinc; Table 6, Fig. 5a). Zinc exposure furthermore caused a decrease in RMR at $20^{\circ} \mathrm{C}$, but an increase at $24^{\circ} \mathrm{C}($ Temperature $\times$ Zinc; Table 6, Fig. 5a).

TABLE 6. Results of the linear mixed models (LMMs) testing for the effect of latitude, rearing temperature, and zinc exposure on routine metabolic rate (RMR) and oxidative damage (malondialdehyde [MDA] levels and carbonyl levels) in Ischnura elegans larvae.

\begin{tabular}{|c|c|c|c|c|c|c|c|c|c|c|c|c|}
\hline \multirow[b]{3}{*}{$\underline{\text { Factor }}$} & \multicolumn{4}{|c|}{ Metabolic rate } & \multicolumn{8}{|c|}{ Oxidative damage } \\
\hline & \multicolumn{4}{|c|}{ RMR } & \multicolumn{4}{|c|}{ Malondialdehyde } & \multicolumn{4}{|c|}{ Carbonyl } \\
\hline & $\mathrm{df}$ & $\chi^{2}$ & $P$ & $\eta_{p}^{2}$ & $\mathrm{df}$ & $\chi^{2}$ & $P$ & $\eta_{p}^{2}$ & $\mathrm{df}$ & $\chi^{2}$ & $P$ & $\eta_{p}^{2}$ \\
\hline Latitude (Lat) & 1 & 68.83 & $<0.001$ & 0.11 & 1 & 0.34 & 0.56 & $<0.001$ & 1 & 2.23 & 0.14 & 0.025 \\
\hline Temp (Te) & 1 & 272.06 & $<0.001$ & 0.30 & 1 & 0.046 & 0.83 & 0.0010 & 1 & 0.49 & 0.48 & 0.0064 \\
\hline Zinc $(\mathrm{Zn})$ & 1 & 0.058 & 0.81 & $<0.001$ & 1 & 4.23 & 0.040 & 0.026 & 1 & 1.95 & 0.026 & 0.056 \\
\hline Lat $\times \mathrm{Te}$ & 1 & 2.66 & 0.10 & 0.0036 & 1 & 4.67 & 0.031 & 0.019 & 1 & 4.33 & 0.037 & 0.053 \\
\hline Lat $\times \mathrm{Zn}$ & 1 & 11.73 & $<0.001$ & 0.017 & 1 & 1.90 & 0.17 & 0.0083 & 1 & 1.02 & 0.31 & 0.014 \\
\hline $\mathrm{Te} \times \mathrm{Zn}$ & 1 & 11.05 & $<0.001$ & 0.017 & 1 & 0.0061 & 0.94 & $<0.001$ & 1 & 3.97 & 0.046 & 0.048 \\
\hline Lat $\times \mathrm{Te} \times \mathrm{Zn}$ & 1 & 1.19 & 0.28 & 0.0018 & 1 & 0.23 & 0.63 & 0.0010 & 1 & 0.16 & 0.69 & 0.0020 \\
\hline
\end{tabular}

Notes: Significant $P$ values $(P<0.05)$ are printed in boldface type. $\eta_{p}^{2}$-values represent effect sizes. 


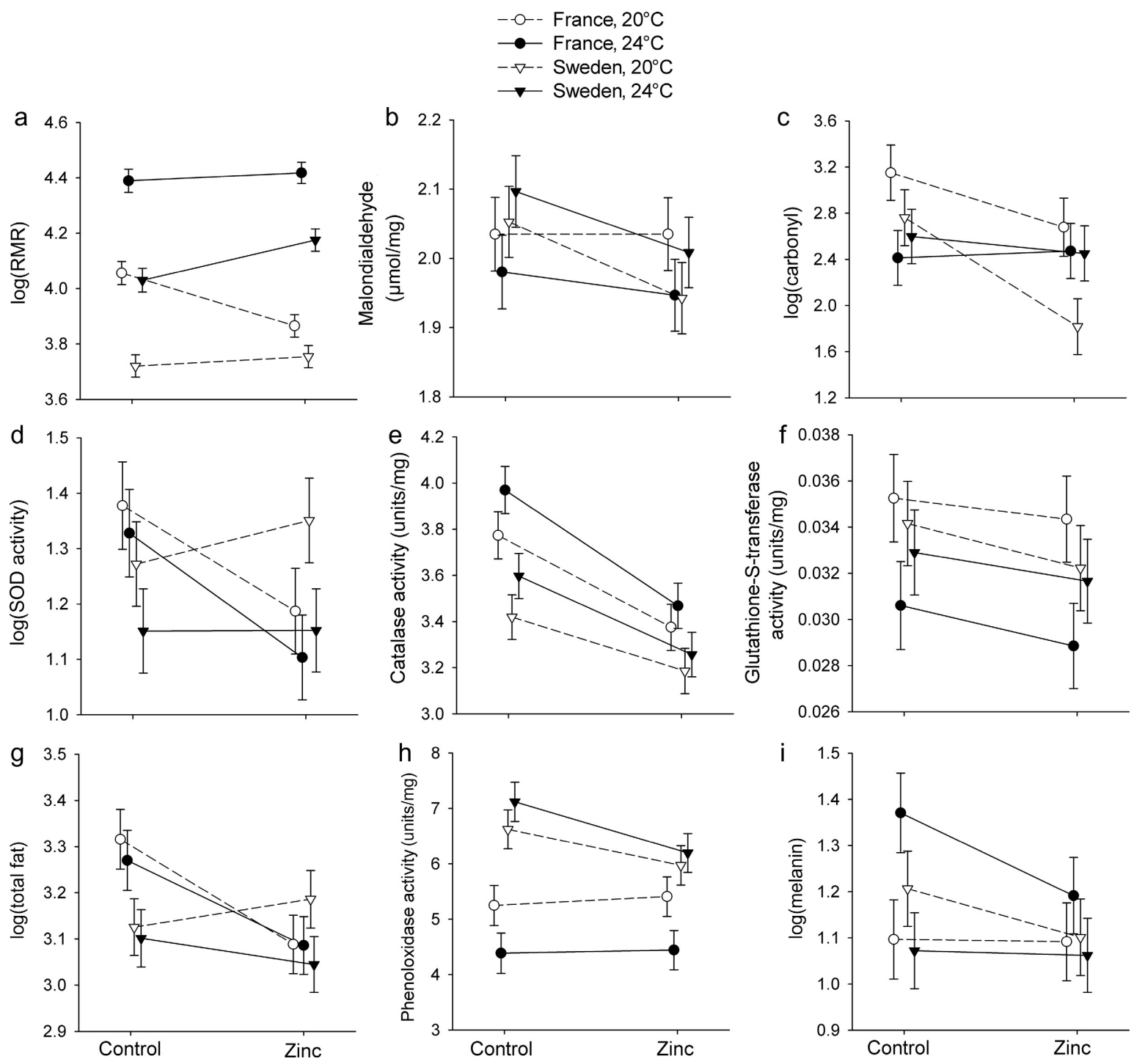

FIG. 5. (a) Routine metabolic rate (RMR, $\mu \mathrm{g} \mathrm{O} \mathrm{O}_{2} \cdot \mathrm{d}^{-1} \cdot \mathrm{g}^{-1}$ ), (b) malondialdehyde (MDA) levels (Box-Cox transformed), (c) carbonyl levels ( $\mathrm{pmol} / \mathrm{mg}$ ), (d) superoxide dismutase (SOD) activity (units $/ \mathrm{mg}$ ), (e) catalase (CAT) activity, (f) glutathione-S-transferase (GST) activity, (g) total fat content ( $\mu \mathrm{g} / \mathrm{mg})$, (h) phenoloxidase (PO) activity, (i) and melanin content ( $\mu \mathrm{g} / \mathrm{mg})$ of Ischnura elegans larvae as a function of latitude, rearing temperature, and zinc exposure. All values are mean $\pm \mathrm{SE}$, expressed per mg wet mass.

Of the three antioxidant enzymes, zinc reduced catalase (CAT) activity and superoxide dismutase (SOD) activity, yet the latter only in French larvae (Latitude $\times$ Zinc), while the glutathione-S-transferase (GST) activity was not affected (Fig. 5b-d, Table 7). At the higher temperature, the activities of SOD and GST decreased, the latter especially in French larvae, while CAT activity increased. Only the CAT activity differed between latitudes with a higher activity in French larvae.

Both measures of oxidative damage (fat damage, malondialdehyde (MDA); protein damage, carbonyls) decreased under zinc exposure, yet for carbonyl this was only true at $20^{\circ} \mathrm{C}$ (Table 6 , Fig. 5e, f). At $24^{\circ} \mathrm{C}$, both levels of MDA and carbonyl decreased in French larvae, while in Swedish larvae MDA instead increased and carbonyl did not react (Table 6, Fig. 5e, f).

Total fat content did not differ between the two temperatures (Table 8). French larvae had a higher fat content than Swedish larvae in the control treatment, but not in the presence of zinc; this was because French larvae decreased fat levels when exposed to zinc, whereas the fat content of Swedish larvae did not differ between zinc treatments (Latitude $\times$ Zinc, Table 8, Fig. 5g). Phenoloxidase (PO) activity was higher in Swedish than in French larvae (main effect Latitude, Table 8, Fig. 5h) and decreased under zinc exposure, but only in Swedish larvae (Latitude $\times$ Zinc, Table 8, Fig. 5h). In French larvae, PO activity decreased at $24^{\circ} \mathrm{C}$ compared to $20^{\circ} \mathrm{C}$, while the opposite was true in Swedish larvae (Latitude $\times$ Temperature, Table 8, Fig. 5h). 
TABLE 7. Results of the linear mixed models (LMMs) testing for the effect of latitude, rearing temperature, and zinc exposure on antioxidant enzymes (superoxide dismutase [SOD] activity, catalase [CAT], activity and glutathione-S-transferase (GST) activity) in Ischnura elegans larvae.

\begin{tabular}{|c|c|c|c|c|c|c|c|c|c|c|c|c|}
\hline \multirow[b]{3}{*}{ Factor } & \multicolumn{12}{|c|}{ Antioxidant enzymes } \\
\hline & \multicolumn{4}{|c|}{ Superoxide dismutase } & \multicolumn{4}{|c|}{ Catalase } & \multicolumn{4}{|c|}{ Glutathione-S-transferase } \\
\hline & $\mathrm{df}$ & $\chi^{2}$ & $P$ & $\eta_{p}^{2}$ & $\mathrm{df}$ & $\chi^{2}$ & $P$ & $\eta_{p}^{2}$ & $\mathrm{df}$ & $\chi^{2}$ & $P$ & $\eta_{p}^{2}$ \\
\hline Latitude (Lat) & 1 & 0.080 & 0.78 & $<0.001$ & 1 & 16.80 & $<0.001$ & 0.084 & 1 & 0.10 & 0.75 & $<0.001$ \\
\hline Temp (Te) & 1 & 5.75 & 0.016 & 0.025 & 1 & 3.84 & 0.050 & 0.013 & 1 & 7.62 & 0.0058 & 0.036 \\
\hline $\operatorname{Zinc}(\mathrm{Zn})$ & 1 & 2.73 & 0.098 & 0.013 & 1 & 28.59 & $<0.001$ & 0.13 & 1 & 1.91 & 0.17 & 0.014 \\
\hline Lat $\times \mathrm{Te}$ & 1 & 0.94 & 0.33 & 0.0038 & 1 & 0.022 & 0.88 & $<0.001$ & 1 & 3.88 & 0.049 & 0.017 \\
\hline Lat $\times \mathrm{Zn}$ & 1 & 6.63 & 0.010 & 0.028 & 1 & 1.43 & 0.23 & 0.0061 & 1 & 0.013 & 0.91 & $<0.001$ \\
\hline $\mathrm{Te} \times \mathrm{Zn}$ & 1 & 0.35 & 0.56 & 0.0015 & 1 & 0.60 & 0.44 & 0.0026 & 1 & $<0.001$ & 0.98 & $<0.001$ \\
\hline Lat $\times \mathrm{Te} \times \mathrm{Zn}$ & 1 & 0.051 & 0.82 & $<0.001$ & 1 & $<0.001$ & 0.99 & $<0.001$ & 1 & 0.13 & 0.81 & $<0.001$ \\
\hline
\end{tabular}

Notes: Significant $P$ values $(P<0.05)$ are printed in boldface type. $\eta_{p}^{2}$-values represent effect sizes.

TABLE 8. Results of the linear mixed models (LMMs) testing for the effect of latitude, rearing temperature, and zinc exposure on markers of body maintenance (total fat content, phenoloxidase [PO] activity, and melanin content) in Ischnura elegans larvae.

\begin{tabular}{|c|c|c|c|c|c|c|c|c|c|c|c|c|}
\hline \multirow[b]{3}{*}{$\underline{\text { Factor }}$} & \multicolumn{12}{|c|}{ Body maintenance } \\
\hline & \multicolumn{4}{|c|}{ Total fat } & \multicolumn{4}{|c|}{ Phenoloxidase } & \multicolumn{4}{|c|}{ Melanin } \\
\hline & $\overline{\mathrm{df}}$ & $\chi^{2}$ & $P$ & $\eta_{p}^{2}$ & $\overline{\mathrm{df}}$ & $\chi^{2}$ & $P$ & $\eta_{p}^{2}$ & $\mathrm{df}$ & $\chi^{2}$ & $P$ & $\eta_{p}^{2}$ \\
\hline Latitude (Lat) & 1 & 2.99 & 0.084 & 0.013 & 1 & 26.27 & $<0.001$ & 0.096 & 1 & 1.84 & 0.18 & 0.0077 \\
\hline Temp (Te) & 1 & 1.59 & 0.21 & 0.0070 & 1 & 1.85 & 0.17 & 0.010 & 1 & 0.57 & 0.45 & 0.0023 \\
\hline Zinc (Zn) & 1 & 5.14 & 0.023 & 0.022 & 1 & 3.68 & 0.055 & 0.023 & 1 & 1.65 & 0.20 & 0.0073 \\
\hline Lat $\times \mathrm{Te}$ & 1 & 0.48 & 0.49 & 0.0018 & 1 & 11.54 & $<0.001$ & 0.047 & 1 & 5.57 & 0.018 & 0.023 \\
\hline Lat $\times \mathrm{Zn}$ & 1 & 5.67 & 0.017 & 0.024 & 1 & 5.75 & 0.016 & 0.025 & 1 & 0.10 & 0.75 & $<0.001$ \\
\hline $\mathrm{Te} \times \mathrm{Zn}$ & 1 & 0.22 & 0.64 & $<0.001$ & 1 & 0.26 & 0.61 & 0.0012 & 1 & 0.087 & 0.77 & $<0.001$ \\
\hline Lat $\times \mathrm{Te} \times \mathrm{Zn}$ & 1 & 0.56 & 0.35 & 0.0037 & 1 & 0.050 & 0.82 & $<0.001$ & 1 & 1.37 & 0.24 & 0.0059 \\
\hline
\end{tabular}

Notes: Significant $P$ values $(P<0.05)$ are printed in boldface type. $\eta_{p}^{2}$-values represent effect sizes.

Melanin levels of Swedish larvae did not differ between temperatures, whereas those of French larvae did (Latitude $\times$ Temperature, Table 7); at $24^{\circ} \mathrm{C}$, French larvae had higher levels of melanin than at $20^{\circ} \mathrm{C}$ and more than Swedish larvae, whereas melanin levels did not differ between latitudes at $20^{\circ} \mathrm{C}$ (Fig. 5i). Zinc exposure did not affect melanin levels (Table 8).

\section{Covariation patterns among the behaviors}

The SEM analysis on the behavioral traits gave most support for model I, indicating that the covariance structure was equal across latitudes and across temperature and zinc treatments (comparison with model IV with second lowest $\mathrm{AIC}_{\mathrm{c}}$ and $\mathrm{BIC}$ values, $\Delta \mathrm{AIC}_{\mathrm{c}}=17.80$, $\Delta \mathrm{BIC}=26.97$, Table 9). The behaviors were largely aligned along an axis from low to high values for activity, exploration, and risk taking. Four out of the six behaviors had loadings significantly different from zero, with more active larvae (longer distance covered in a non-novel, non-risky environment), also being more exploratory (longer distance covered in a new environment) and more risk taking (longer distance covered under predation threat and, to a lesser extent, higher food intake under predation threat; Fig. 6).

\section{Covariation patterns among the physiological traits}

The SEM analysis on the physiological traits also showed model I (covariance structure equal across latitudes and across temperature and zinc treatments) to have the lowest $\mathrm{AIC}_{\mathrm{c}}$ and $\mathrm{BIC}$ values (comparison with model IV with second lowest $\mathrm{AIC}_{\mathrm{c}}$ and $\mathrm{BIC}$ values, $\Delta \mathrm{AIC}_{\mathrm{c}}=93.54$, $\Delta \mathrm{BIC}=27.34$, Table 9). Based on model I, all eight physiological traits had loadings significantly different from zero. The physiology latent variable was mainly determined by glutathione-S-transferase (GST) and malondialdehyde (MDA) with larvae with lower GST levels, having higher levels of oxidative damage (MDA). These larvae also had higher activity levels of catalase (CAT) and superoxide dismutase (SOD), and accumulated more fat and melanin, and to a lesser extent had a lower metabolic rate and lower phenoloxidase (PO) activity levels (Fig. 6).

\section{Overall syndrome structure}

The overarching SEM analysis integrating life history, behavior, and physiology indicated model I to have the lowest $\mathrm{AIC}_{\mathrm{c}}$ (comparison with second best supported model IV, $\Delta \mathrm{AIC}_{\mathrm{c}}=309.37, \Delta \mathrm{BIC}=93.54$, Table 9). This indicates the overall syndrome structure is consistent across 
TABLE 9. Model comparison results for the pace of life syndrome (POLS)-related structural equation models (SEMs).

\begin{tabular}{|c|c|c|c|c|}
\hline Model & $\mathrm{AIC}_{\mathrm{c}}$ & $\Delta \mathrm{AIC}_{\mathrm{c}}$ & $\mathrm{BIC}$ & $\Delta \mathrm{BIC}$ \\
\hline \multicolumn{5}{|c|}{ Behavioral SEMs } \\
\hline $\mathbf{I}$ & 4203.97 & 0.00 & 4022.28 & 0.00 \\
\hline II & 4229.96 & 25.99 & 4057.44 & 35.16 \\
\hline III & 4233.92 & 29.95 & 4061.4 & 39.12 \\
\hline IV & 4221.77 & 17.8 & 4049.25 & 26.97 \\
\hline $\mathrm{V}$ & 4283.92 & 79.95 & 4143.8 & 121.52 \\
\hline VI & 4273.01 & 69.04 & 4132.89 & 110.61 \\
\hline VII & 4274.13 & 70.16 & 4134.01 & 111.73 \\
\hline VIII & 4379.49 & 175.52 & 4388.79 & 366.51 \\
\hline \multicolumn{5}{|c|}{ Physiological SEMs } \\
\hline $\mathbf{I}$ & 5235.39 & 0.00 & 5292.29 & 0.00 \\
\hline II & 5337.47 & 102.08 & 5328.17 & 35.88 \\
\hline III & 5341.56 & 106.17 & 5332.26 & 39.97 \\
\hline IV & 5328.93 & 93.54 & 5319.63 & 27.34 \\
\hline $\mathrm{V}$ & 5611.37 & 375.98 & 5391.11 & 98.82 \\
\hline VI & 5608.53 & 373.14 & 5388.27 & 95.98 \\
\hline VII & 5613.51 & 378.12 & 5393.25 & 100.96 \\
\hline VIII & 6974.94 & 1739.55 & 5515.88 & 223.59 \\
\hline \multicolumn{5}{|c|}{ Full POLS SEMs } \\
\hline I & 4694.57 & 0.00 & 5235.39 & 0.00 \\
\hline II & 5007.21 & 312.64 & 5337.47 & 102.08 \\
\hline III & 5004.09 & 309.53 & 5341.56 & 106.17 \\
\hline IV & 5003.93 & 309.37 & 5328.93 & 93.54 \\
\hline $\mathrm{V}$ & 5483.74 & 789.18 & 5611.37 & 375.98 \\
\hline VI & 5483.91 & 789.35 & 5608.53 & 373.14 \\
\hline VII & 5478.98 & 784.42 & 5613.51 & 378.12 \\
\hline VIII & 6097.27 & 1402.7 & 6974.94 & 1739.55 \\
\hline
\end{tabular}

Notes: Each alternative model tested for a different combination of factor loading constraints across the eight treatment groups (2 latitude, 2 rearing temperatures, 2 zinc treatments), as presented in Table 1. The overarching full POLS SEMs were based on the bestfitting models for behavior and physiology. Best models (as indicated by the lowest $\mathrm{AIC}_{\mathrm{c}}$ and $\mathrm{BIC}$ ) are indicated in boldface type.

latitudes, temperatures, and zinc levels. Based on model I, growth rate, and the two latent variables capturing behavior (trend) and physiology were integrated in an overarching syndrome structure. According to this model, larvae with a higher growth rate tended $(P=0.074)$ to be positively associated with the behavior latent variable (more active, explorative, and risk taking) and had higher values for the physiology latent variable (mainly lower glutathione-Stransferase [GST] levels and higher levels of malondialdehyde [MDA]). For both the French and the Swedish populations, this overarching model 1 had a better fit when loadings were set equal across populations within a given latitude compared to when loadings were allowed to vary freely across populations within a given latitude (French, $\Delta \mathrm{BIC}=112.39, \Delta \mathrm{AIC}_{\mathrm{c}}=7.04 ;$ Swedish,$\Delta \mathrm{BIC}=126.38$, $\left.\Delta \mathrm{AIC}_{\mathrm{c}}=45.82\right)$. This indicates that populations within a given latitude did not differ in POLS structure.

\section{Discussion}

\section{POLS across latitudes: latitudinal differentiation in trait means}

Across latitudes, growth rate, behavior and physiology integrated into a syndrome. Consistent with the POLS hypothesis, the fast-paced French damselflies were characterized by a fast growth rate, proactive behavior, fast metabolic rate, and low investment in immune function. The faster pace of life in French larvae is associated with a disproportional increase in the number of generations (three or four generations per year) compared to Swedish populations (one generation per two years; Corbet et al. 2006).

In accordance with their faster pace of life, French larvae were consistently more active, explorative, and risk taking than Swedish larvae, as shown by the longer distances covered in the three contexts, shorter latency to feed on a novel food item, and a higher food intake under predation threat. While previous studies reported similar latitudinal differences where the fast-lived populations were also more active and/or risk taking (e.g., Tieleman et al. 2006, Chiba et al. 2007), we were able to show this for an integrated set of traits covering activity, exploration, and risk taking. The higher risk taking behavior of the French larvae (and more specifically the longer distances travelled in the presence of the predator) translated into a higher susceptibility to predation (at $24^{\circ} \mathrm{C}$ ). While a trade-off between susceptibility to predation and having a fast lifestyle has been considered important in maintaining differences in lifestyle (Werner and Anholt 1993, Stamps 2007, Wolf et al. 2007), 


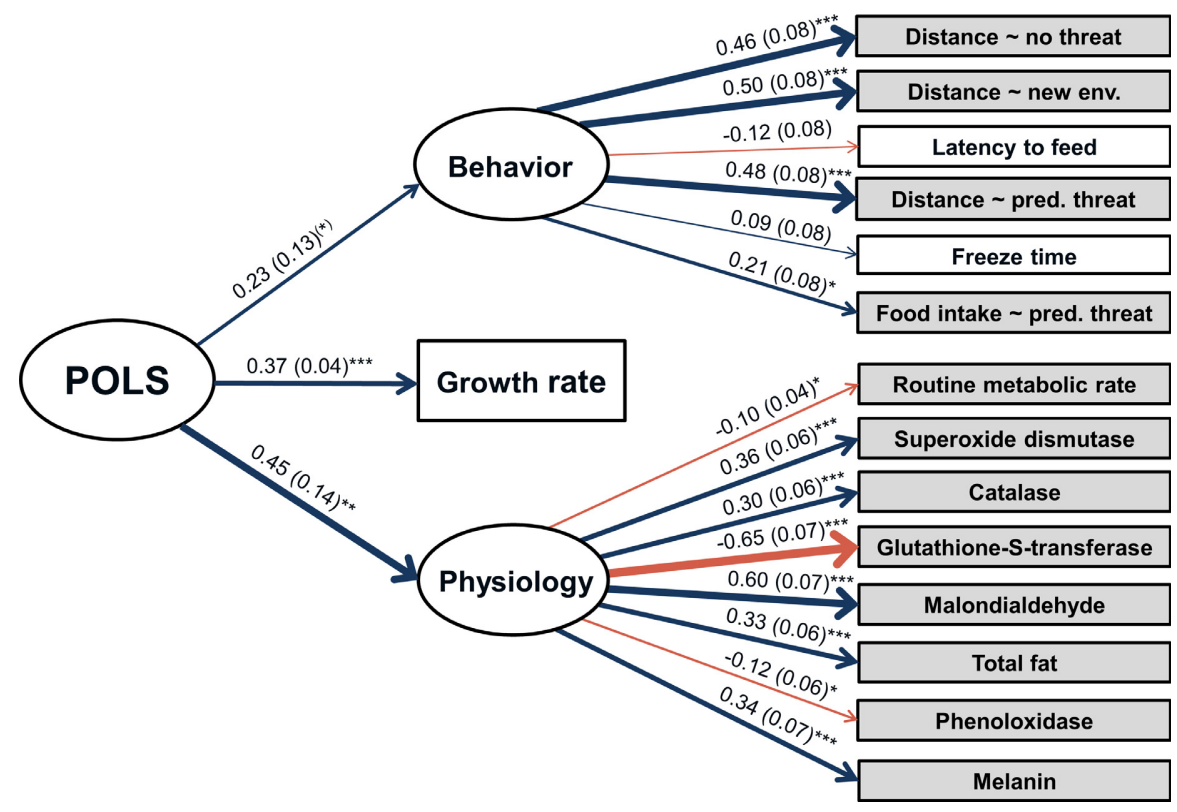

FIG. 6. Structural equation models (SEMs) showing the covariance structure within the set of behaviors, within the set of physiological traits, and within the overarching pace of life syndrome. Numbers associated with arrows are standardized factor loadings (given with $1 \mathrm{SE}$ ), and represent how many SD the specific trait is predicted to change based on a $1 \mathrm{SD}$ change in underlying syndrome structure (similarly as regression or correlation coefficients; Brown 2006). The thickness of the arrows is proportional to the strength of the path loadings. Asterisks indicate whether a factor loading is significantly different from zero $\left({ }^{(*)} 0.10>P>0.05 ; * 0.05>P>0.01\right.$; $* * 0.01>P>0.001 ; * * * P<0.001)$. Boxes of behavioral and physiological variables with significant loadings are shaded.

relatively few studies, all on vertebrates, have reported it at the population level (e.g., Lankford et al. 2001, Munch et al. 2003, Laurila et al. 2006, 2008). While at $20^{\circ} \mathrm{C}$ French larvae also behaved more actively and took more risks than the Swedish larvae, at this temperature they were not more susceptible to predation. A higher escape swimming speed of the French larvae (see Janssens et al. 2014a) might have compensated for a high behavior-mediated susceptibility.

The latitudinal differences in physiological traits were less pronounced than the differences in life history and behavioral traits. Nevertheless, fast-lived French larvae had a higher routine metabolic rate (RMR, $+29 \%)$ than the slow-lived Swedish larvae, matching the POLS hypothesis. This supports other studies showing intraspecific differences in metabolic rate connected to latitude-specific growth rate (e.g., Billerbeck et al. 2000, Lahti et al. 2002, Wikelski et al. 2003, Lardies et al. 2004). Patterns of antioxidant defense and oxidative stress biomarkers were more similar across latitudes, except for catalase (CAT) activity being higher in French than in Swedish larvae. The latter contrasts with the prediction of a lower investment in body maintenance in fast-lived organisms (Roff 1992, Stearns 1992). This could be the response to a higher production of reactive oxygen species (ROS) in French larvae (cf. Jimenez et al. 2014), which seemed effectively neutralized as they did not show increased levels of oxidative damage.

Consistent with previous results (Janssens et al. 2014b, Op de Beeck et al. 2017), fat content was highest in French larvae, whereas phenoloxidase (PO) activity was highest in Swedish larvae. This might indicate fat content being traded off against PO activity; also changes in both traits after zinc exposure suggested this (Latitudinal differences in dealing with zinc exposure). Given the general occurrence of resource-allocation trade-offs between growth and energy storage (Boggs 2009), the relatively high investment in energy storage in French larvae is surprising given their fast pace (Gotthard 2001), but is in line with previous findings in fish, where fast-growing populations allocated more energy to lipid storage (Schultz and Conover 1997). As animals were fed ad libitum, we cannot exclude that a trade-off between growth and energy storage would become detectable under food shortage (Forsman and Lindell 1991).

\section{Effects of warming on trait means suggest thermal adaptation}

French larvae grew faster at $24^{\circ} \mathrm{C}$ than at $20^{\circ} \mathrm{C}$ $(+25 \%)$. In sharp contrast, the growth rate of Swedish larvae at $24^{\circ} \mathrm{C}$ was almost one-half of that at $20^{\circ} \mathrm{C}$ $(-46 \%)$, indicating that $24^{\circ} \mathrm{C}$ is suboptimal for them. Given that the chosen temperatures reflect the current average summer water temperatures in southern Sweden $\left(20^{\circ} \mathrm{C}\right)$ and in southern France $\left(24^{\circ} \mathrm{C}\right.$; Appendix S2; De Block et al. 2013), these observations are consistent with differential thermal adaptation between these latitudes. Note, however, that as we worked with offspring from 
field-collected mothers our design cannot exclude a role of maternal effects. While French and Swedish larvae showed opposite growth responses to the higher temperature, they both had a higher routine metabolic rate (RMR) at $24^{\circ} \mathrm{C}$ than at $20^{\circ} \mathrm{C}$. This mismatch confirms that growth rate and metabolic rate might be less functionally coupled than widely assumed (see also Burton et al. 2011, Glazier 2015). Under a global warming scenario with an expected $4^{\circ} \mathrm{C}$ temperature increase by 2100 (scenario RC8.5; IPCC 2014) and in the absence of gradual thermal evolution, the slower growth of high-latitude animals might translate into a slower population growth rate (lower voltinism), possibly precluding population persistence. This further indicates the importance of thermal evolution compared to thermal plasticity for populations to persist locally (Gunderson and Stillman 2015). As non-adaptive plasticity can reinforce evolution by increasing the strength of directional selection (Ghalambor et al. 2015, Stoks et al. 2016), thermal evolution may offset negative effects of a temperature increase on highlatitude animals via strong selection for a fast lifestyle (as present in the low-latitude animals currently already experiencing mean water summer temperatures $4^{\circ} \mathrm{C}$ higher than in the high-latitude populations).

For most behaviors, we observed a latitudinal difference in the response to temperature that was similar to the pattern we found for growth rate. Indeed, French larvae mostly increased activity, exploration and risk taking at $24^{\circ} \mathrm{C}$ compared to $20^{\circ} \mathrm{C}$, while Swedish larvae mostly showed the opposite response under warming. This suggests that besides growth rate also behavior showed a pattern of thermal adaptation.

Thermal responses of the set of physiological variables related to maintenance were partly latitude specific. In response to warming, the levels of both oxidative damage biomarkers decreased in French larvae (cfr. Vinagre et al. 2012, Kazerouni et al. 2015) while malondialdehyde (MDA) levels increased in Swedish larvae. This suggests a physiological signal of thermal adaptation with French larvae dealing better with higher temperatures than Swedish larvae. This could not be explained by changes in antioxidant enzymes under warming (catalase [CAT] activity increased and superoxide dismutase [SOD] activity decreased at both latitudes, and glutathione-S-transferase [GST] activity decreased in French larvae), indicating other mechanisms were also at play. Furthermore, only French larvae accumulated higher melanin levels at $24^{\circ} \mathrm{C}$ than at $20^{\circ} \mathrm{C}$, leading to higher levels than Swedish larvae at $24^{\circ} \mathrm{C}$. The response of a darker cuticle at higher temperatures has been observed before (e.g., Galeotti et al. 2009, Prokkola et al. 2013). The observation that this only happened in French larvae may reflect the higher natural UV levels in France compared to Sweden (SoDa Service 2013), and that Swedish larvae experienced $24^{\circ} \mathrm{C}$ as suboptimal while melanin is costly to produce (Talloen et al. 2004, Stoehr 2006). UV radiation has been shown to drive population differences in pigmentation across latitudes
(Bastide et al. 2014). In addition, as melanin is also part of the immune system (Siva-Jothy et al. 2005) the higher melanin levels under warming may reflect a higher investment in immune function in the French larvae to counteract their lower phenoloxidase (PO) activity.

\section{Latitude-wide effects of zinc exposure on trait means}

Zinc exposure modestly decreased survival, but strongly reduced growth rate, which can be explained by the here observed lower food intake and/or by an upregulation of defense and repair mechanisms (Gillis et al. 2002, Dinh Van et al. 2013). Zinc furthermore made larvae less active, less exploratory, and less risk taking (except for freeze time), which matches behavioral effects of metals on feeding activity and antipredator behavior (Mogren and Trumble 2010, for the study species; Janssens et al. 2014a). The zinc-induced behavioral responses can be explained by neurological effects combined with a decreased oxygen uptake and increased metabolic costs (Clarkson 1987, Sokolova and Lannig 2008). Even though zinc exposure affected all behaviors, there was no effect of the metal on survival times in the predation trial. Likely, the reduction in freeze time, which makes larvae more easily detectable by predators, was compensated by a reduced level of most other behaviors, which would decrease detectability.

While zinc, if anything, reduced the activity of antioxidant enzymes (catalase (CAT) and superoxide dismutase (SOD) in French larvae), this was unexpectedly associated with a decrease in oxidative damage (malondialdehyde [MDA] and carbonyl). Although other studies have also reported decreased levels of oxidative damage after an oxidant challenge (Lushchak et al. 2005, Bagnyukova et al. 2006), the underlying mechanisms are poorly understood (Belyaeva et al. 2008).

\section{Latitudinal differences in dealing with zinc exposure}

Overall, French larvae were more sensitive to zinc than Swedish larvae (in terms of growth, routine metabolic rate [RMR], superoxide dismutase [SOD], and fat content). Zinc induced a stronger decrease in growth rate in the fast-lived French than in the slow-lived Swedish larvae, which supports the idea that the pace of life could shape sensitivity to contaminants (Dinh Van et al. 2014, Baas and Kooijman 2015). Zinc exposure also reduced RMR in French larvae, while RMR in Swedish was upregulated. Low levels of stress have been shown to induce metabolic upregulation (cfr. Swedish larvae), indicating an active investment in detoxification and damage repair, whereas high levels of stress rather lead to metabolic depression (cfr. French larvae) (Hand and Hardewig 1996, Sokolova and Lannig 2008). Only for phenoloxidase (PO) activity, the Swedish larvae seemed more sensitive as only they reduced PO activity under zinc exposure. Yet, even the reduced PO levels were still higher than the levels observed in French larvae, which 
may suggest that the French tried to maintain a minimum level of immune function.

\section{Trait covariation patterns across latitudes, zinc, and temperature treatments}

Within latitudes, growth, behavior, and physiology were largely integrated into an overarching syndrome. The covariance structures between the behavioral traits and between the physiological traits as well as the overall syndrome structure were consistent across latitudes, despite considerable latitudinal divergence in trait means. Such stability of trait associations across large geographic scales has been documented before for behavioral syndromes (Pruitt et al. 2010, Alcalay et al. 2015, Bengston and Dornhaus 2015, but see Segev et al. 2017), but had never been tested for an integrated set of life history, behavioral, and physiological traits. Our finding of no large-scale differentiation in syndrome structure is conservative as our methodology does not exclude maternal effects, which if present, would be promoting differentiation, rather than consistency across latitudes. Note that the POLS implies the presence of non-zero between-individual correlations (Dingemanse et al. 2013). As we did not measure trait repeatability, the provided pairwise phenotypic correlations will only approximate the between-individual correlations when both traits have high repeatability, otherwise they will overestimate the latter (Dingemanse et al. 2013).

While exposure to environmental stressors, here pollutants and warming, is expected to change the covariation patterns between traits (Killen et al. 2013, Montiglio and Royauté 2014) this was not observed. Indeed, neither warming nor zinc exposure changed the covariation patterns within the set of behavioral traits or within the set of physiological traits, neither did it affect the overall trait integration. For behavior, the consistent pattern reflected the expected coupling of more active animals also being more explorative and more risk taking. This contrasts with previous studies where contaminant exposure either induced a coupling between two behaviors (Brodin et al. 2013) or disrupted behavioral correlations (Royauté et al. 2015a, Dzieweczynski et al. 2016). In contrast to the expectations, behavior was less strongly integrated into the syndrome (see also Debecker et al. 2016).

For physiology, the consistent covariation pattern showed larvae with lower levels of the secondary antioxidant glutathione-S-transferase (GST), suffered more oxidative damage to lipids (measured as malondialdehyde [MDA]) despite having higher levels of catalase (CAT) and superoxide dismutase (SOD). Furthermore, these larvae accumulated more fat and melanin but invested less in phenoloxidase (PO), suggesting a similar trade-off between fat content and PO activity as seen across latitudes. Remarkably, the routine metabolic rate (RMR) was only weakly integrated within the physiological trait set. This is surprising as metabolic rate is often considered as one of the key traits driving consistent individual differences (Biro and Stamps 2010, Réale et al. 2010, but see Glazier 2015), but confirms previous findings of a limited association between metabolic rate and other physiological traits (e.g., Buehler et al. 2012, Versteegh et al. 2012). Because of this limited role of RMR and the unexpected positive covariation between investment in body maintenance (the antioxidant enzymes SOD and CAT, energy reserves, and melanin) and oxidative damage (MDA), it was not possible to identify the "fast vs. slow" differentiation within the physiological trait set that was predicted based on the verbal POLS model (Réale et al. 2010). Yet, it should be noted that these physiological traits have not been formally included in theoretical POLS models (Mathot and Frankenhuis 2018).

Taken together, at the phenotypic level, the behavioral variables covaried in such a way that more active larvae were also more explorative and risk taking, which aligned with the fast-slow life history axis, but less strong than at the across-latitude level. Although physiological traits were also integrated into a syndrome within latitudes, there was no unambiguous coupling with the fastslow life history continuum. Therefore, within latitudes, there was no full support for the verbal POLS model of Réale et al. (2010), thereby matching the emerging pattern that multi-trait studies tend to show deviations from the POLS expectations (e.g., Niemelä et al. 2013, Debecker et al. 2016, Monceau et al. 2017, reviewed in Royauté et al. 2018). Damselflies of different latitudes did, however, show a consistent pattern in phenotypic trait correlations that was not affected by warming and metal exposure, suggesting that the syndrome structure sets restrictions to independent responses of individual traits to global change (assuming phenotypic associations are underpinned by genetic correlations). These results contrast with the pronounced latitudinal differences in trait means and in their responses to warming across latitudes. While our finding of consistent covariation structures across latitudes suggests that trait integration may restrict the independent evolution of single traits, this may not necessarily constrain adaptive evolution of the integrated trait set. Indeed, the covariance pattern was similar across latitudes and within latitudes, suggesting adaptive trait integration potentially guiding adaptive evolution of trait sets along the fast-slow continuum. Specifically, the latitudinal differences between the fast French larvae compared to the slow Swedish larvae were to a large extent paralleled at the phenotype level within populations: with both faster (French) populations and faster larvae within populations having a higher growth rate, higher levels of activity, exploration, and risk taking, and higher levels of catalase (CAT), fat, and melanin and lower levels of phenoloxidase (PO). This similar covariance pattern among and within populations suggests either strong pleiotropy or correlational selection acting on interdependent traits in the same way at both latitudes (scenario B in Fig. 3 of Peiman and Robinson 2017). A relevant next question is whether and 
how such consistent syndrome structure affects individual fitness along environmental gradients (Laughlin and Messier 2015) and shape communities and ecosystems (cfr. Pruitt and Modlmeier 2015, Royauté and Pruitt 2015, Start and Gilbert 2017). Improving our insight in the occurrence and implications of intraspecific trait covariation along latitudinal gradients will be pivotal to improve trait-based predictions of species and community responses to global change (Laughlin and Messier 2015).

\section{ACKNOWLEDGMENTS}

We thank Philippe Lambret and Viktor Nilsson-Örtman for collecting the damselfly eggs. We are very grateful to Vienna Delnat and Julie Verheyen for the field campaign to characterize the study lakes and to Kiani Cuypers and Nathan De Fruyt for afterward processing the field samples. We acknowledge the assistance during the experiment of Lizanne Janssens, Khuong Van Dinh, Sarah Oexle, Astrid Maetens, Rony Van Aerschot, and Mattia Walschaers. Nedim Tüzün engaged in valuable discussions on the statistics. Comments by Sharon Lawler and three anonymous reviewers considerably improved the manuscript. S. Debecker was supported by a Ph.D. fellowship of the Research Foundation-Flanders (FWO). This study was financed by research grants from FWO (G.0704.13 and G.0524.17) and the KU Leuven (C16/17/002).

\section{Literature Cited}

Adler, G. H., and R. Levins. 1994. The island syndrome in rodent populations. Quarterly Review of Biology 69:473-490.

Aho, K., D. Derryberry, and T. Peterson. 2014. Model selection for ecologists: the worldviews of AIC and BIC. Ecology 95:631-636.

Aho, K., D. Derryberry, and T. Peterson. 2017. A graphical framework for model selection criteria and significance tests: refutation, confirmation and ecology. Methods in Ecology and Evolution 8:47-56.

Alcalay, Y., I. Scharf, and O. Ovadia. 2015. Foraging syndromes and trait variation in antlions along a climatic gradient. Oecologia 178:1093-1103.

Angilletta, M. J. 2009. Thermal adaptation: a theoretical and empirical synthesis. Oxford University Press, New York, New York, USA

Baas, J., and S. A. L. M. Kooijman. 2015. Sensitivity of animals to chemical compounds links to metabolic rate. Ecotoxicology 24:657-663.

Bagnyukova, T. V., O. I. Chahrak, and V. I. Lushchak. 2006. Coordinated response of goldfish antioxidant defenses to environmental stress. Aquatic Toxicology 78:325-331.

Bastide, H., A. Yassin, E. J. Johanning, and J. E. Pool. 2014. Pigmentation in Drosophila melanogaster reaches its maximum in Ethiopia and correlates most strongly with ultra-violet radiation in sub-Saharan Africa. BMC Evolutionary Biology 14:179.

Bates, D., M. Maechler, B. Bolker, and S. Walker. 2014. lme4: Linear mixed-effects models using Eigen and S4. R package version 1.0-6. http://CRAN.R-project.org/package=lme4

Belyaeva, E. A., D. Dymkowska, M. R. Więckowski, and L. Wojtczak. 2008. Mitochondria as an important target in heavy metal toxicity in rat hepatoma AS-30D cells. Toxicology and Applied Pharmacology 231:34-42.

Bengston, S. E., and A. Dornhaus. 2015. Latitudinal variation in behaviors linked to risk tolerance is driven by nest-site competition and spatial distribution in the ant Temnothorax rugatulus. Behavioral Ecology and Sociobiology 69:12651274.

Billerbeck, J. M., E. T. Schultz, and D. O. Conover. 2000. Adaptive variation in energy acquisition and allocation among latitudinal populations of the Atlantic silverside. Oecologia 122:210-219.

Biro, P. A., and J. A. Stamps. 2008. Are animal personality traits linked to life-history productivity? Trends in Ecology \& Evolution 23:361-368.

Biro, P. A., and J. A. Stamps. 2010. Do consistent individual differences in metabolic rate promote consistent individual differences in behavior? Trends in Ecology \& Evolution 25:653659.

Biro, P. A., C. Beckmann, and J. A. Stamps. 2010. Small withinday increases in temperature affects boldness and alters personality in coral reef fish. Proceedings of the Royal Society B 277:71-77.

Blanckenhorn, W. U., and M. Demont. 2004. Bergmann and converse Bergmann latitudinal clines in arthropods: two ends of a continuum? Integrative and Comparative Biology 44:413-424.

Bligh, E. G., and W. J. Dyer. 1959. A rapid method of total lipid extraction and purification. Canadian Journal of Biochemistry and Physiology 37:911-917.

Boggs, C. L. 2009. Understanding insect life histories and senescence through a resource allocation lens. Functional Ecology 23:27-37.

Boyle, W. A., B. K. Sandercock, and K. Martin. 2015. Patterns and drivers of intraspecific variation in avian life history along elevational gradients: a meta-analysis. Biological Reviews 91:469-482.

Bradford, M. M. 1976. A rapid and sensitive method for the quantification of microgram quantities of protein, utilizing the principle of protein-dye landing. Analytical Biochemistry 72:248-254.

Brix, K. V., D. K. DeForest, and W. J. Adams. 2011. The sensitivity of aquatic insects to divalent metals: A comparative analysis of laboratory and field data. Science of the Total Environment 409:4187-4197.

Brodin, T. 2009. Behavioral syndrome over the boundaries of life - carryovers from larvae to adult damselfly. Behavioral Ecology 20:30-37.

Brodin, T., J. Fick, M. Jonsson, and J. Klaminder. 2013. Dilute concentrations of a psychiatric drug alter behavior of fish from natural populations. Science 339:814-815.

Brook, B. W., N. S. Sodhi, and C. J. A. Bradshaw. 2008. Synergies among extinction drivers under global change. Trends in Ecology \& Evolution 23:453-460.

Brown, T. A. 2006. Confirmatory factor analysis for applied research. Guilford Publications, New York, New York, USA.

Brown, A. L., and B. W. Robinson. 2016. Variation in behavioural plasticity regulates consistent individual differences in Enallagma damselfly larvae. Animal Behaviour 112:63-73.

Buehler, D. M., F. Vezina, W. Goymann, I. Schwabl, M. Versteegh, B. I. Tieleman, and T. Piersma. 2012. Independence among physiological traits suggests flexibility in the face of ecological demands on phenotypes. Journal of Evolutionary Biology 25:1600-1613.

Burnham, K. P., and D. R. Anderson. 2002. Model selection and multimodel inference: a practical information-theoretic approach. Springer, New York, New York, USA.

Burnham, K. P., and D. R. Anderson. 2004. Multimodel inference: understanding AIC and BIC in model selection. Sociological Methods \& Research 33:261-304.

Burton, T., S. S. Killen, J. D. Armstrong, and N. B. Metcalfe. 2011. What causes intraspecific variation in resting metabolic 
rate and what are its ecological consequences? Proceedings of the Royal Society B 278:3465-3473.

Canli, M., and G. Atli. 2003. The relationships between heavy metal $(\mathrm{Cd}, \mathrm{Cr}, \mathrm{Cu}, \mathrm{Fe}, \mathrm{Pb}, \mathrm{Zn})$ levels and the size of six Mediterranean fish species. Environmental Pollution 121:129-136.

Careau, V., S. S. Killen, and N. B. Metcalfe. 2014. Adding fuel to the fire of life: energy budgets across levels of variation in ectotherms and endotherms. Pages 219-233 in L. B. Martin, C. K. Ghalambor, and A. W. Woods, editors. Integrative organismal biology. Wiley, Hoboken, New Jersey, USA.

Carnicer, J., A. Barbeta, D. Sperlich, M. Coll, and J. Peñuelas. 2013. Contrasting trait syndromes in angiosperms and conifers are associated with different responses of tree growth to temperature on a large scale. Frontiers in Plant Science 4:119.

Cayuela, H., L. Boualit, D. Arsovski, E. Bonnaire, J. Pichenot, A. Bellec, C. Miaud, J. P. Léna, P. Joly, and A. Besnard. 2016. Does habitat unpredictability promote the evolution of a colonizer syndrome in amphibian metapopulations? Ecology 97:2658-2670.

Chappell, M. A., T. Garland, E. L. Rezende, and F. R. Gomes. 2004. Voluntary running in deer mice: speed, distance, energy costs and temperature effects. Journal of Experimental Biology 207:3839.

Chiba, S., S. A. Arnott, and D. O. Conover. 2007. Coevolution of foraging behavior with intrinsic growth rate: risk-taking in naturally and artificially selected growth genotypes of Menidia menidia. Oecologia 154:237-246.

Clarkson, T. W. 1987. Metal toxicity in the central nervous system. Environmental Health Perspectives 75:59-64.

Congdon, J. D., A. E. Dunham, W. A. Hopkins, C. L. Rowe, and T. G. Hinton. 2001. Resource allocation-based life histories: A conceptual basis for studies of ecological toxicology. Environmental Toxicology and Chemistry 20:1698-1703.

Conover, D. O., T. A. Duffy, and L. A. Hice. 2009. The covariance between genetic and environmental influences across ecological gradients. Annals of the New York Academy of Sciences 1168:100-129.

Corbet, P. S., F. Suhling, and D. Soendgerath. 2006. Voltinism of Odonata: a review. International Journal of Odonatology 9:1-44.

Cotter, S. C., L. E. B. Kruuk, and K. Wilson. 2004. Costs of resistance: genetic correlations and potential trade-offs in an insect immune system. Journal of Evolutionary Biology 17:421-429.

De Block, M., and R. Stoks. 2004. Cannibalism-mediated life history plasticity to combined time and food stress. Oikos 106:587-597.

De Block, M., and R. Stoks. 2008. Compensatory growth and oxidative stress in a damselfly. Proceedings of the Royal Society B 275:781-785.

De Block, M., K. Pauwels, M. Van Den Broeck, L. De Meester, and R. Stoks. 2013. Local genetic adaptation generates latitude-specific effects of warming on predator-prey interactions. Global Change Biology 19:689-696.

De Frenne, P., F. Rodríguez-Sánchez, D. A. Coomes, L. Baeten, G. Verstraeten, M. Vellend, M. Bernhardt-Römermann, C. D. Brown, J. Brunet, and J. Cornelis. 2013. Microclimate moderates plant responses to macroclimate warming. Proceedings of the National Academy of Sciences USA 110:18561-18565.

Debecker, S., R. Sommaruga, T. Maes, and R. Stoks. 2015. Larval UV exposure impairs adult immune function through a trade-off with larval investment in cuticular melanin. Functional Ecology 29:1292-1299.
Debecker, S., I. Sanmartín-Villar, M. de Guinea-Luengo, A. Cordero-Rivera, and R. Stoks. 2016. Integrating the pace-oflife syndrome across species, sexes and individuals: covariation of life history and personality under pesticide exposure. Journal of Animal Ecology 85:726-738.

Dingemanse, N. J., J. Wright, A. J. N. Kazem, D. K. Thomas, R. Hickling, and N. Dawnay. 2007. Behavioural syndromes differ predictably between 12 populations of three-spined stickleback. Journal of Animal Ecology 76:1128-1138.

Dingemanse, N. J., N. A. Dochtermann, and M. van de Pol. 2013. Quantifying individual variation in behaviour: mixedeffect modelling approaches. Journal of Animal Ecology 82:39-54.

Dinh Van, K., L. Janssens, S. Debecker, M. Jonge, P. Lambret, V. Nilsson-Örtman, L. Bervoets, and R. Stoks. 2013. Susceptibility to a metal under global warming is shaped by thermal adaptation along a latitudinal gradient. Global Change Biology 19:2625-2633.

Dinh Van, K., L. Janssens, S. Debecker, and R. Stoks. 2014. Temperature-and latitude-specific individual growth rates shape the vulnerability of damselfly larvae to a widespread pesticide. Journal of Applied Ecology 51:919-928.

Doutrelant, C., M. Paquet, J. P. Renoult, A. Grégoire, P.-A. Crochet, and R. Covas. 2016. Worldwide patterns of bird colouration on islands. Ecology Letters 19:537-545.

Dzieweczynski, T. L., B. A. Campbell, and J. L. Kane. 2016. Dose-dependent fluoxetine effects on boldness in male Siamese fighting fish. Journal of Experimental Biology 219:797804.

EC (European Communities). 2010. European Union risk assessment report-zinc metal. EC (European Communities), Bilthoven, The Netherlands.

Forsman, A. 2015. Rethinking phenotypic plasticity and its consequences for individuals, populations and species. Heredity 115:276-284.

Forsman, A., and L. E. Lindell. 1991. Trade-off between growth and energy storage in male Vipera berus (L.) under different prey densities. Functional Ecology 5:717-723.

Fukami, T., and D. A. Wardle. 2005. Long-term ecological dynamics: reciprocal insights from natural and anthropogenic gradients. Proceedings of the Royal Society B 272:2105-2115.

Galeotti, P., D. Rubolini, R. Sacchi, and M. Fasola. 2009. Global changes and animal phenotypic responses: melanin-based plumage redness of scops owls increased with temperature and rainfall during the last century. Biology Letters 5:532534.

Ghalambor, C. K., K. L. Hoke, E. W. Ruell, E. K. Fischer, D. N. Reznick, and K. A. Hughes. 2015. Non-adaptive plasticity potentiates rapid adaptive evolution of gene expression in nature. Nature 525:372-375.

Gillis, P. L., L. C. Diener, T. B. Reynoldson, and D. G. Dixon. 2002. Cadmium-induced production of a metallothioneinlike protein in Tubifex tubifex (Oligochaeta) and Chironomus riparius (Diptera): Correlation with reproduction and growth. Environmental Toxicology and Chemistry 21:1836-1844.

Glazier, D. S. 2015. Is metabolic rate a universal 'pacemaker' for biological processes? Biological Reviews 90:377-407.

González-Santoyo, I., and A. Córdoba-Aguilar. 2012. Phenoloxidase: a key component of the insect immune system. Entomologia Experimentalis et Applicata 142:1-16.

Gosden, T. P., R. Stoks, and E. I. Svensson. 2011. Range limits, large-scale biogeographic variation, and localized evolutionary dynamics in a polymorphic damselfly. Biological Journal of the Linnean Society 102:775-785.

Gotthard, K. 2001. Growth strategies of ectothermic animals in temperate environments. Pages 287-304 in D. Atkinson and 
M. Thorndyke, editors. Environment and animal development. BIOS Scientific, Oxford, UK.

Gunderson, A. R., and J. H. Stillman. 2015. Plasticity in thermal tolerance has limited potential to buffer ectotherms from global warming. Proceedings of the Royal Society B 282:20150401.

Gvoždík, L., and R. Smolinský. 2015. Body size, swimming speed, or thermal sensitivity? Predator-imposed selection on amphibian larvae. BMC Evolutionary Biology 15:238.

Gyssels, F. G. M., and R. Stoks. 2005. Threat-sensitive responses to predator attacks in a damselfly. Ethology 111:411-423.

Hand, S. C., and I. Hardewig. 1996. Downregulation of cellular metabolism during environmental stress: mechanisms and implications. Annual Review of Physiology 58:539-563.

Hille, S. M., and C. B. Cooper. 2015. Elevational trends in life histories: revising the pace-of-life framework. Biological Reviews 90:204-213.

IPCC (Intergovernmental Panel on Climate Change). 2014. Climate change 2013: the physical science basis: Working Group I contribution to the Fifth assessment report of the Intergovernmental Panel on Climate Change. Cambridge University Press, Cambridge, UK.

Janssens, L., and R. Stoks. 2012. How does a pesticide pulse increase vulnerability to predation? Combined effects on behavioral antipredator traits and escape swimming. Aquatic Toxicology 110:91-98.

Janssens, L., and R. Stoks. 2013. Synergistic effects between pesticide stress and predator cues: Conflicting results from life history and physiology in the damselfly Enallagma cyathigerum. Aquatic Toxicology 132:92-99.

Janssens, L., and R. Stoks. 2018. Rapid larval development under time stress reduces adult lifespan through increasing oxidative damage. Functional Ecology 32:10361045 .

Janssens, L., K. Dinh Van, S. Debecker, L. Bervoets, and R. Stoks. 2014a. Local adaptation and the potential effects of a contaminant on predator avoidance and antipredator responses under global warming: a space-for-time substitution approach. Evolutionary Applications 7:421-430.

Janssens, L., K. Dinh Van, and R. Stoks. 2014b. Extreme temperatures in the adult stage shape delayed effects of larval pesticide stress: A comparison between latitudes. Aquatic Toxicology 148:74-82.

Jimenez, A. G., C. Cooper-Mullin, E. A. Calhoon, and J. B. Williams. 2014. Physiological underpinnings associated with differences in pace of life and metabolic rate in north temperate and neotropical birds. Journal of Comparative Physiology B 184:545-561.

Kazerouni, E. G., C. E. Franklin, and F. Seebacher. 2015. UV-B radiation interacts with temperature to determine animal performance. Functional Ecology 30:584-595.

Killen, S. S., S. Marras, N. B. Metcalfe, D. J. McKenzie, and P. Domenici. 2013. Environmental stressors alter relationships between physiology and behaviour. Trends in Ecology \& Evolution 28:651-658.

Korashy, H. M., and A. O. S. El-Kadi. 2006. The role of aryl hydrocarbon receptor and the reactive oxygen species in the modulation of glutathione transferase by heavy metals in murine hepatoma cell lines. Chemico-Biological Interactions 162:237-248.

Korsloot, A., C. A. M. Van Gestel, and N. M. Van Straalen. 2004. Environmental stress and cellular response in arthropods. CRC Press, Boca Raton, Florida, USA

Lahti, K., H. Huuskonen, A. Laurila, and J. Piironen. 2002. Metabolic rate and aggressiveness between brown trout populations. Functional Ecology 16:167-174.
Lakens, D. 2013. Calculating and reporting effect sizes to facilitate cumulative science: a practical primer for t-tests and ANOVAs. Frontiers in Psychology 4:863.

Lankford, T. E., J. M. Billerbeck, and D. O. Conover. 2001. Evolution of intrinsic growth and energy acquisition rates. II. Trade-offs with vulnerability to predation in Menidia menidia. Evolution 55:1873-1881.

Lardies, M. A., L. D. Bacigalupe, and F. Bozinovic. 2004. Testing the metabolic cold adaptation hypothesis: an intraspecific latitudinal comparison in the common woodlouse. Evolutionary Ecology Research 6:567-578.

Laughlin, D. C., and J. Messier. 2015. Fitness of multidimensional phenotypes in dynamic adaptive landscapes. Trends in Ecology \& Evolution 30:487-496.

Laurila, A., S. Pakkasmaa, and J. Merilä. 2006. Population divergence in growth rate and antipredator defences in Rana arvalis. Oecologia 147:585-595.

Laurila, A., B. Lindgren, and A. T. Laugen. 2008. Antipredator defenses along a latitudinal gradient in Rana temporaria. Ecology 89:1399-1413.

Londono, G. A., M. A. Chappell, M. D. R. Castañeda, J. E. Jankowski, and S. K. Robinson. 2015. Basal metabolism in tropical birds: latitude, altitude, and the 'pace of life'. Functional Ecology 29:338-346.

Lushchak, V. I. 2011. Environmentally induced oxidative stress in aquatic animals. Aquatic Toxicology 101:13-30.

Lushchak, V. I., T. V. Bagnyukova, V. V. Husak, L. I. Luzhna, V. Lushchak, and K. B. Storey. 2005. Hyperoxia results in transient oxidative stress and an adaptive response by antioxidant enzymes in goldfish tissues. International Journal of Biochemistry \& Cell Biology 37:1670-1680.

Mathot, K. J., and W. E. Frankenhuis. 2018. Models of pace-oflife syndromes (POLS): a systematic review. Behavioral Ecology and Sociobiology 72:41.

McLoughlin, N., D. Yin, L. Maltby, R. M. Wood, and H. Yu. 2000. Evaluation of sensitivity and specificity of two crustacean biochemical biomarkers. Environmental Toxicology and Chemistry 19:2085-2092.

Merilä, J., and A. P. Hendry. 2014. Climate change, adaptation, and phenotypic plasticity: the problem and the evidence. Evolutionary Applications 7:1-14.

Miyamoto, S., E. Alves de Almeida, L. Nogueira, M. H. Gennari de Medeiros, and P. Di Mascio. 2011. Evaluation of malondialdehyde levels. Pages 440-447 in J. Abele, J. P. Vazquez-Medina, and T. Zenteno-Savin, editors. Oxidative stress in aquatic ecosystems. Wiley Blackwell, Oxford, UK.

Mogren, C. L., and J. T. Trumble. 2010. The impacts of metals and metalloids on insect behavior. Entomologia Experimentalis et Applicata 135:1-17.

Monaghan, P., N. B. Metcalfe, and R. Torres. 2009. Oxidative stress as a mediator of life history trade-offs: mechanisms, measurements and interpretation. Ecology Letters 12:75-92.

Monceau, K., F. X. Dechaume-Moncharmont, J. Moreau, C. Lucas, R. Capoduro, S. Motreuil, and Y. Moret. 2017. Personality, immune response and reproductive success: An appraisal of the pace-of-life syndrome hypothesis. Journal of Animal Ecology 86:932-942.

Montiglio, P. O., and R. Royauté. 2014. Contaminants as a neglected source of behavioural variation. Animal Behaviour 88:29-35.

Munch, S. B., D. O. Conover, and P. Wainwright. 2003. Rapid growth results in increased susceptibility to predation in Menidia menidia. Evolution 57:2119-2127.

Niemelä, P. T., N. J. Dingemanse, N. Alioravainen, A. Vainikka, and R. Kortet. 2013. Personality pace-of-life hypothesis: testing genetic associations among personality and life history. Behavioral Ecology 24:935-941. 
Noyes, P. D., M. K. McElwee, H. D. Miller, B. W. Clark, L. A. Van Tiem, K. C. Walcott, K. N. Erwin, and E. D. Levin. 2009. The toxicology of climate change: environmental contaminants in a warming world. Environment International 35:971-986.

Op de Beeck, L., J. Verheyen, K. Olsen, and R. Stoks. 2017. Negative effects of pesticides under global warming can be counteracted by a higher degradation rate and thermal adaptation. Journal of Applied Ecology 54:1847-1855.

Peiman, K. S., and B. W. Robinson. 2017. Comparative analyses of phenotypic trait covariation within and among populations. American Naturalist 190:451-468.

Prokkola, J., D. Roff, T. Kärkkäinen, I. Krams, and M. J. Rantala. 2013. Genetic and phenotypic relationships between immune defense, melanism and life-history traits at different temperatures and sexes in Tenebrio molitor. Heredity 111:8996.

Pruitt, J. N., and A. P. Modlmeier. 2015. Animal personality in a foundation species drives community divergence and collapse in the wild. Journal of Animal Ecology 84:1461-1468.

Pruitt, J. N., S. E. Riechert, and T. C. Jones. 2008. Behavioural syndromes and their fitness consequences in a socially polymorphic spider, Anelosimus studiosus. Animal Behaviour 76:871-879.

Pruitt, J. N., S. E. Riechert, G. Iturralde, M. Vega, B. M. Fitzpatrick, and L. Aviles. 2010. Population differences in behaviour are explained by shared within-population trait correlations. Journal of Evolutionary Biology 23:748-756.

R Core Team. 2013. R: A language and environment for statistical computing. R Foundation for Statistical Computing, Vienna, Austria. http://www.R-project.org/

Réale, D., S. M. Reader, D. Sol, P. T. McDougall, and N. J. Dingemanse. 2007. Integrating animal temperament within ecology and evolution. Biological Reviews 82:291-318.

Réale, D., D. Garant, M. M. Humphries, P. Bergeron, V. Careau, and P.-O. Montiglio. 2010. Personality and the emergence of the pace-of-life syndrome concept at the population level. Philosophical Transactions of the Royal Society B: Biological Sciences 365:4051-4063.

Ricklefs, R. E., and M. Wikelski. 2002. The physiology/life-history nexus. Trends in Ecology \& Evolution 17:462-468.

Roff, D. A. 1992. Life history evolution. Sinauer Associates, Sunderland, Massachusetts, USA.

Rosseel, Y. 2012. Lavaan: an R package for structural equation modeling. Journal of Statistical Software 48:1-36.

Roulin, A. 2014. Melanin-based colour polymorphism responding to climate change. Global Change Biology 20:3344-3350.

Royauté, R., and J. N. Pruitt. 2015. Varying predator personalities generates contrasting prey communities in an agroecosystem. Ecology 96:2902-2911.

Royauté, R., C. M. Buddle, and C. Vincent. 2015a. Under the influence: sublethal exposure to an insecticide affects personality expression in a jumping spider. Functional Ecology 29:962-970.

Royauté, R., K. Greenlee, M. Baldwin, and N. A. Dochtermann. 2015b. Behaviour, metabolism and size: phenotypic modularity or integration in Acheta domesticus? Animal Behaviour 110:163-169.

Royauté, R., M. A. Berdal, C. R. Garrison, and N. A. Dochtermann. 2018. Paceless life? A meta-analysis of the pace-of-life syndrome hypothesis. Behavioral Ecology and Sociobiology 72:64.

Rubach, M. N., R. Ashauer, D. B. Buchwalter, H. J. De Lange, M. Hamer, T. G. Preuss, K. Töpke, and S. J. Maund. 2011. Framework for traits-based assessment in ecotoxicology. Integrated Environmental Assessment and Management 7:172-186.
Sarkar, A., D. Ray, A. N. Shrivastava, and S. Sarker. 2006. Molecular biomarkers: their significance and application in marine pollution monitoring. Ecotoxicology 15:333-340.

Schlichting, C. D., and M. Pigliucci. 1998. Phenotypic evolution: a reaction norm perspective. Sinauer Associates, Sunderland, UK.

Schlichting, C. D., and M. A. Wund. 2014. Phenotypic plasticity and epigenetic marking: an assessment of evidence for genetic accommodation. Evolution 68:656-672.

Schultz, E. T., and D. O. Conover. 1997. Latitudinal differences in somatic energy storage: adaptive responses to seasonality in an estuarine fish (Atherinidae: Menidia menidia). Oecologia 109:516-529.

Segev, U., L. Burkert, B. Feldmeyer, and S. Foitzik. 2017. Paceof-life in a social insect: behavioral syndromes in ants shift along a climatic gradient. Behavioral Ecology 28:1149-1159.

Shama, L. N. S., M. Campero-Paz, K. Wegner, M. De Block, and R. Stoks. 2011. Latitudinal and voltinism compensation shape thermal reaction norms for growth rate. Molecular Ecology 20:2929-2941.

Shipley, B. 2002. Cause and correlation in biology: a user's guide to path analysis, structural equations and causal inference. Cambridge University Press, Cambridge, UK.

Siva-Jothy, M. T., Y. Moret, and J. Rolff. 2005. Insect immunity: an evolutionary ecology perspective. Advances in Insect Physiology 32:1-48.

Slos, S., and R. Stoks. 2006. Behavioural correlations may cause partial support for the risk allocation hypothesis in damselfly larvae. Ethology 112:143-151.

SoDa Service. 2013. Solar energy services for professionals. http://www.soda-is.com

Sokolova, I. M., and G. Lannig. 2008. Interactive effects of metal pollution and temperature on metabolism in aquatic ectotherms: implications of global climate change. Climate Research 37:181-201.

Stamps, J. A. 2007. Growth-mortality tradeoffs and 'personality traits' in animals. Ecology Letters 10:355-363.

Start, D., and B. Gilbert. 2017. Predator personality structures prey communities and trophic cascades. Ecology Letters 20:366-374.

Stearns, S. C. 1992. The evolution of life histories. Oxford University Press, Oxford, UK.

Stevens, V. M., A. Trochet, S. Blanchet, S. Moulherat, J. Clobert, and M. Baguette. 2013. Dispersal syndromes and the use of life-histories to predict dispersal. Evolutionary Applications 6:630-642.

Stevens, V. M., S. Whitmee, L. Galliard, J. Clobert, K. Böhning-Gaese, D. Bonte, M. Brändle, D. Matthias Dehling, C. Hof, and A. Trochet. 2014. A comparative analysis of dispersal syndromes in terrestrial and semi-terrestrial animals. Ecology Letters 17:1039-1052.

Stoehr, A. M. 2006. Costly melanin ornaments: the importance of taxon? Functional Ecology 20:276-281.

Stoks, R., M. De Block, and M. A. McPeek. 2005. Alternative growth and energy storage responses to mortality threats in damselflies. Ecology Letters 8:1307-1316.

Stoks, R., M. De Block, and M. A. McPeek. 2006a. Physiological costs of compensatory growth in a damselfly. Ecology 87:1566-1574.

Stoks, R., M. De Block, S. Slos, W. Van Doorslaer, and J. Rolff. 2006b. Time constraints mediate predator-induced plasticity in immune function, condition, and life-history. Ecology 87:809-815.

Stoks, R., I. Swillen, and M. De Block. 2012. Behaviour and physiology shape the growth accelerations associated with predation risk, high temperatures and southern latitudes in 
Ischnura damselfly larvae. Journal of Animal Ecology 81:1034-1040.

Stoks, R., A. N. Geerts, and L. De Meester. 2014. Evolutionary and plastic responses of freshwater invertebrates to climate change: realized patterns and future potential. Evolutionary Applications 7:42-55.

Stoks, R., L. Govaert, K. Pauwels, B. Jansen, and L. De Meester. 2016. Resurrecting complexity: the interplay of plasticity and rapid evolution in the multiple trait response to strong changes in predation pressure in the water flea Daphnia magna. Ecology Letters 19:180-190.

Storey, K. B. 1996. Oxidative stress: animal adaptations in nature. Brazilian Journal of Medical and Biological Research 29:1715-1733.

Talloen, W., H. Van Dyck, and L. Lens. 2004. The cost of melanization: butterfly wing coloration under environmental stress. Evolution 58:360-366.

Tanaka, Y., and M. Hisada. 1980. The hydraulic mechanism of the predatory strike in dragonfly larvae. Journal of Experimental Biology 88:1-20.

Tattersall, G. J., B. J. Sinclair, P. C. Withers, P. A. Fields, F. Seebacher, C. E. Cooper, and S. K. Maloney. 2012. Coping with thermal challenges: physiological adaptations to environmental temperatures. Comprehensive Physiology 2:2151-2202.

Tieleman, B. I., J. B. Williams, R. E. Ricklefs, and K. C. Klasing. 2005. Constitutive innate immunity is a component of the pace-of-life syndrome in tropical birds. Proceedings of the Royal Society B 272:1715-1720.

Tieleman, B. I., T. H. Dijkstra, J. R. Lasky, R. A. Mauck, G. H. Visser, and J. B. Williams. 2006. Physiological and behavioural correlates of life-history variation: a comparison between tropical and temperate zone house wrens. Functional Ecology 20:491-499.

Tilman, D., J. Fargione, B. Wolff, C. Antonio, A. Dobson, R. Howarth, D. Schindler, W. H. Schlesinger, D. Simberloff, and D. Swackhamer. 2001. Forecasting agriculturally driven global environmental change. Science 292:281-284.

Ton, R., and T. E. Martin. 2015. Metabolism correlates with variation in post-natal growth rate among songbirds at three latitudes. Functional Ecology 30:743-748.
Tüzün, N., S. Debecker, L. Op de Beeck, and R. Stoks. 2015. Urbanisation shapes behavioural responses to a pesticide. Aquatic Toxicology 163:81-88.

Tüzün, N., S. Müller, K. Koch, and R. Stoks. 2017. Pesticideinduced changes in personality depend on the urbanization level. Animal Behaviour 134:45-55.

Van Steertegem, M. (editor) 2010. MIRA Indicatorrapport 2010, Milieurapport Vlaanderen, Vlaamse Milieumaatschappij. https://www.milieurapport.be/publicaties/2010/crisis-ve rsterkt-trend-van-dalende-druk-opmilieu

Versteegh, M. A., I. Schwabl, S. Jaquier, and B. I. Tieleman. 2012. Do immunological, endocrine and metabolic traits fall on a single pace-of-life axis? Covariation and constraints among physiological systems. Journal of Evolutionary Biology 25:1864-1876.

Vinagre, C., D. Madeira, L. Narciso, H. N. Cabral, and M. Diniz. 2012. Effect of temperature on oxidative stress in fish: lipid peroxidation and catalase activity in the muscle of juvenile seabass, Dicentrarchus labrax. Ecological Indicators 23:274-279.

Werner, E. E., and B. R. Anholt. 1993. Ecological consequences of the trade-off between growth and mortality rates mediated by foraging activity. American Naturalist 142:242272 .

Wiersma, P., A. Muñoz-Garcia, A. Walker, and J. B. Williams. 2007. Tropical birds have a slow pace of life. Proceedings of the National Academy of Sciences USA 104:9340-9345.

Wikelski, M., L. Spinney, W. Schelsky, A. Scheuerlein, and E. Gwinner. 2003. Slow pace of life in tropical sedentary birds: a common-garden experiment on four stonechat populations from different latitudes. Proceedings of the Royal Society B 270:2383-2388.

Wolf, M., G. S. Van Doorn, O. Leimar, and F. J. Weissing. 2007. Life-history trade-offs favour the evolution of animal personalities. Nature 447:581-584.

Zhou, J., J. Shang, F. Ping, and G. Zhao. 2012. Alcohol extract from Vernonia anthelmintica L. wild seed enhances melanin synthesis through activation of the p38 MAPK signaling pathway in B16F10 cells and primary melanocytes. Journal of Ethnopharmacology 143:639-647.

SUPPORTING INFORMATION

Additional supporting information may be found online at: http://onlinelibrary.wiley.com/doi/10.1002/ecm.1332/full

Data Availability

Data associated with this paper are available from the Dryad Digital Repository: https://doi.org/10.5061/dryad.p39r7kh 